\title{
Die Stadt Luna und ihr Gebiet.
}

\section{Ein Beitrag zar historischen Landeskunde Italiens.}

Von

\section{Julius Jung.}

Die historische Landeskunde von Italien muss naturgemäss ihren Ausgang nehmen von den Nachrichten, die aus der Zeit der römisı hen Herrschaft stammen und nach dieser Richtung hin leistet das Werk von Heinrich $\mathrm{N}$ issen alles, was möglich ist. Dennoch ergebeu sich sofort auch für das Alterthum bedeutende Ergänzungen, wenn man den Quellenkreis über Paulus diaconus hinaus erweitert uud das Erlöschen antiker Städte in Betracht zieht, das ebenso von Interesse ist, wie das Emporkommen neuer Bevölkerungscentren in Folge der geänderten Existenzbedingungen.

Onter den Städten, von denen sowohl das Datum der Gründung als das Datum des Unterganges genau feststeht, ist Luna zu nennen. Luna hatte, als es officiell für eine , città morta " erklärt wurde, nämlich im J. $1204 \mathrm{n}$. Chr. ein Alter von 1381 Jahren erreicht. Es hatte in dieser Zeit gute und böse Tage gesehen; fast dreihundert Jahre lang war es eine der bedeutenderen Seestädte Italiens gewesen, dessen Name in entscheidenden Momenten, so als das Pasttluum und das fräukische Königthum sich über das Schicksal der Apenniuenhulbinsel verständigten, vor allen anderen genannt wurde ${ }^{1}$ ). Als dann

1) Wir längnen nicht, dass zunächst dieser Umstand unsere Aufmrrksamkeit auf Luna gelenkt hat. Die Pacta der römischen Kirche sind für die geographisch-historische Forschung in jeder Beziehung ein Hilfsmittel ersten Runges. - Auf die Apenninübergänge ist schon in dem Aufsatz über ,Bobbio, Veleia, Bardi • (Mitth. d. Instituts, Bd. XX) Rücksicht genommen worden. Zu diesem Aufsatze bildet der vorliegende ein Supplement, da er die Dinge von der ánderen Seite des Gebirges betrachtet. 
Italien zur See überall den Kürzeren zog, ausser wo in Felsschluchten wie bei Amalfi oder in schwerzugänglichen Lagunen wie bei Venedig die Natur selbst vor Angriffen schützte, da ereilte auch Luna das Ungläck; ja dieses wiederholte sich. Die Stadt wurde von den Nachbarorten überflügelt, die Bevölkerung zog weg und schliesslich zwang die „böse Luft“ zu völliger Uebersiedlung, die nach den in jener Zeit gebräuchiichen Ceremonien erfolgte. Wir haben es also hier mit einer städtischen Individualität zu thun, deren Wachsthum und deren Niedergang wir uns genau vergegenwärtigeu können. Nirgends ersieht man so deutlich, wie aus geographisch gegebenen Verhültnissen die Geschichte einer Stadt sich herauswächst; und nicht bloss der Stadt, sondern auch der dazu gehörigen Landschaft, die als "Lunigiana" den Namen von Luna weiter propagirte. Wir haben diese Studie durchgeführt, weil nirgends in der nüchstliegenden Litteratur die erwïnschte Aufkläruug zu finden war, vielmehr zahlreiche Widersprüche in den Angaben Verwunderung erregten ${ }^{1}$ ). Möge sie als Baustein zu einer historischeu Laudeskunde Italiens angesehen werden, zu deren Bearbeitung es früher oder später kommen muss, u. $\mathrm{zw}$. nicht bloss vom antiquarischen Standpunkt aus, der von Nissen und den Bearbeitern des Lateiuischen Inschriftenwerkes in vortrefflicher Weise wahrgenommen ist, sondern auch vom Standpunkt eines durch das Studium der Urkunden des Nittelalters erweiterten Gesichtskreises'). Als dritter Factor mag daun inmerhin noch die Auschauung des gegenwärtigen aber auch in beständiger Entwicklung begriffenen Landschaftsbildes hinzutreten, da man dadurch die dem Gesammturtheil zu Grınde liegeuden Thatsachen vorh um ein weitcres zu vermehren im Stande ist.

Die Positionen von Pisae und Luca werden schon zur Zeit des zweit $n$ punischen Krieges erwähnt, erstere als Ausgangspunkt für die Expeditionen nach Hispanien, letztere für den Verkehr über den Apennin nach Placentia. Mag die betreffende Notiz bei T. Livius auch zu kri-

1) Vgl. z. B. Ewald zu Gregorii M. reg. IV, 21: „Luna Etruriae urbs, haud procul ab ostio Macrae fluminis. Aut Lunegiano (!) aut Sarzana hodierna oppida in loco eius constructa esse putantur*. Auch über die Zerstörung ron Luna findet man auseinandergehende Angaben, vgl. Corp. inscript. Lat. XI p. 259. Mitth. d. Instituts IV 607.

2) Daraus ergibt sich von selbst die Kritik von Nissens, Italischer Landeskunde. Wenn z. B. S. 306 de'm Flusse Auser (d. i. Serchio-Auserculus) die Schiffluarkeit abgesprochen wird, so kann man durch die Urkunden für Luca saec. XI, XIl (Sium) if Reg. 28.34, 3274) das Gegentheil erweisen. Nach Cassiodor. Var. F, 17 ward vom König Theoderich vorgesorgt, dass die Sthiffuhrt durch den Firschfaing nicht gehindert werde; dabei wird unter anderen Flüesen auch der Auser genannt. 
tischen Bemängelungen Anlass geben ${ }^{1)}$ so würde gleichwohl für die Zeit, da der Geschichtschrciber seiu Werk abfasste, die Beziehung Luca's zu dem Apenninenverkelır dargethan sein, die uns andererseits durch die Alimentartufeln bestätigt wird. Die Stadtgemeinde von Luca erscheint darin als Nachbarin der Stadtgemeinde Veleia, indem sie am Uebergang über den Apenuin (unfern der Quellen des Auser, jetzt Serchio) einen Complex von Gründen in ihrem Besitz hatte' ${ }^{2}$ ). Von diesen Stälten reichte Pisae in die altetruskische Zeit zurück, worauf es als civitas foederata dem rönischen Staatsverband einverleibt wurde. Seit dem Bundesgenossenkriege ist es municipium und als solches der tribus Galeria zugeschritben ${ }^{3}$ ). Lucu wurde zur Zeit der Ligurcrkriege, die dem Hanuibalischen folgten, in J. 180 v. Chr. als Colonie Latinischen Pechtes constituirt, nicht ohne dass die Pisaner dafür einen Theil ihres Gebittes hergegeben hätten ${ }^{4}$ ). Eudlıch wurde im J. 177 v. Chr. theils auf Pisanischem theils auf den Ligurern abgenommenem Gebiet am Fluss Macra eine $\mathrm{rom}$ is che Colonie Namens Luna begründet ${ }^{5}$ ), un von hier aus das obere Macrathal und deu Pass

1) Liv. 21, 59: Hannibal in Ligures, Sempronius Lucam concessit. Vgl. biezu Bornann in Corp. inse. Lat. XI, p. $258 \mathrm{f}$. Ueber Pisie ebenda p. $272 \mathrm{f}$. Die er.te Erwähnung geschieht bei Polyb. 2, 27, 1, wonach der Consul A. Atilius im J. 225 aus Sardinien kommend bei Pisae landet. Ueber den Verkehr von Placentia nach Pisae vgl. Liv. 40, 41.

2) Vgl. Beloch, Der Italische Bund unter Roms Hegemonie (Leipzig 1880) S. 148. Mein ,Bobbio“ S. 539.

s) Die Galeria ist die Tribus dieser ligurischen Striche, der auch Luna zugeschrieben worden war. Luca hingegen erhirlt die Tribus Fabia. Vgl. die Karte 1 zu Beloch, Der italische Bund. - Die Pluralform Pisae wird im Alterthum constant gebraucht, während für Luna djese Form nur in den , promissiones" Pippins und harls (a Luniss) und noch einmal im 9. Jahrhundert (M. G. Leg. 1, 50.) vorkommt. Vgl. Corp. XI p. 272. 259. (Die Itinerarien, auch Geogr. Rav. und Guido Pisanus haben: Lune).

4) Lir. 40, 43. Vgl. Bormann Corp. XI p. 295.

5) Liv. 41, 13: et [L]una[m] colonia eodem anno duo milia civium Romanorum sunt deducta. - quinquagena et singula iugera et semisses agri in singulos dati sunt. de Ligure is captus ager erat; Etruscorum ante quam Ligurum fuerat. Im J. 168 gab es Streitigkeiten zwischen den coloni von Luna und den Pisanern wegen des ager. Liv. 45, 13. Im J. 15j warf der Consul M. Clandius Marcellus eine Erhebung der Ligurer und Apuani nieder, wofür er in Rom tr umphirte (tabnl. triumph.) und in Luna auf dem Fornm ein Denkmal erhielt. Vgl. Corp. I $538=$ XI 1339 - Der Name Luna scheint ligurischen Ursprungs zu sein; vgl. Frontin. strateg. 3, 2, 1 : Luna oppidum Ligurum, dessen Belingerung durch die Römer besprochen wird. Auch an etruskjschen Ursprung könnte man denken, wenn man z. B. Vetluna (= Vetulonia) oder Pupluna (= Populonia, resp. Populonium) vergleicht. - Syäter deutete man den Namen auf die 
über den Apennin zu beherrschen, nachdem man den früher hier sesshaften Stamm der Ligurer, die Apuaner, expatriirt und gewaltsam nach Samnium verpflanzt hatte: vierzigtausend Köpfe im J. 180, weitere siebentausend im J. 179 v. Chr. ${ }^{1}$ ). Seit 109 v. Chr. führte die nach dem Censor M. Aemilius Scaurus benannte via Aemilia von Volaterrae über Pisae nach Luna, von wo sie nach Genua weitergieng. Zugleich hatte man die Bedeutung der Position von Luna für die Beherrschung des Ligurischen Meeres und seiner Inseln erkannt²); der Hafen oder vielmehr der Complex von grösseren und kleineren Laudungsplätzen in dem geräumigen G»lf von Luna gelangte bei den Römern rasch zu Ruf, seit der in Versen politisirende Ennius ihn den Bürgern empfohlen hatte ${ }^{3}$ ). Er eignete sich (im Zusammenhange mit der Strasse) vortrefflich zum Ausgangspunkt der Seefahrt nach Massilia und nach Hispanien. Wir besitzen eine anschauliche Beschreibung desselben bei Strabo, der die Stadt klein, den Hafen aber gross und schön nennt4). Man überblicke von den umgebenden Bergen weithin das Meer, die Insel Sardivien (vielmehr Corsica!), die Küste des Festlandes.

Im Uebrigen wechselten in diesem ligurisch-etruskischen Grenzwinkel die politischen Zutheilungen wiederholt. Es scheint, dass Pisae erst seit Sulla zu Italien gezählt wurde, während Luca in Julius Caesar's Zeit noch zu dessen Provincialsprengel gehörte. Dann trat eine Aenderung ein; denn als Augustus die Regionen Italiens feststellte, finden wir als Grenze zwischen der 7. Region (Etrurien) und der 9. Region (Ligurien) die Macra bestimmt5). Das war für Luna insofern von Be-

Mondgöttin Luna (griechisch Selene) um; nach Persius Flaceus gab die sichelförınig gekrümmte Linie des Hafens dazu den Anlass.

1) Liv. 40, 38; 41. Vgl. Hülsen s. v. Apuani in Pauly-Wissowa's Realencyclopädie. Die Ligurer bevorzugten die Wohnsitze in den Bergen, besonders an den Passübergängen. Die Römer erzwangen die Besiedelung der Ebene (wie in Italien so auch in den Provinzen).

2) Von dem Consul d. J. 185 v. Chr. berichtet Liv. 39, 32, dass er von Pisa aus gegen die Apuani mit Feuer und Schwert vorgegangen sei: aperuit saltum usque ad Macram et Lunae portum. - Es ist der Golf von Spezia, zwischen den Vorgebirgen von Portovenere und Punta Bianca, Vgl. Nissen a. a. 0.231.

9) Ennius citirt von Persins sat. 6, 9: Lunai portum, est operae, cognoscite cives.

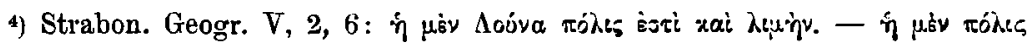

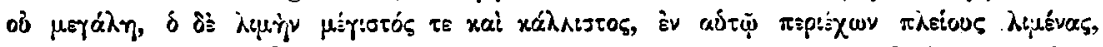

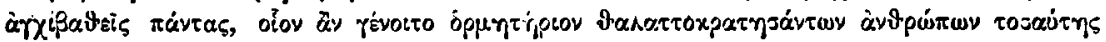

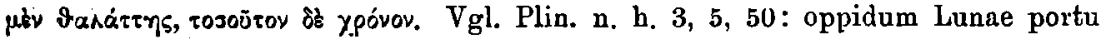
nobile. Andere Belege bei Bormann 1. c.

5) Vgl. Mommsen, Die Regionen Italiens. In der Kiepert-Festschrift S. 103. 
deutung, als die Stadt (und die Marmorbrüche) diesseits des Flusses lagen, während ihr Haupthafen jenseits, also auf ligurischem Gebiet sich befand; eine Zwieschlächtigkeit, die auch bei den geographischen Schriftstellern der Epoche zum Ausdruck kommt. Denn während Mela Luna zu ligurien rechnet, zählt es Plinius zu Etrurien; es war eben das eine so richtig, wie das andere; das Territorium von Luna bildete beiderseits die Greuze, das "Confinium". An der Mündung der Macra lag, wenn wir Strabo recht verstehen, ein Ankerplatz1). Nach den Angaben des Küstenitinerars fuhr man zu Schiff von Pisa nach Luna an die Macra 30 Millien weit ${ }^{2}$ ). Dabei scheint die Flotte von Misenum wie in Corsica so auch in Luna eine Station unterbalten zu haben ${ }^{3}$ ). Luna war in der Kaiserzeit der Stapelplatz für die Producte, die das Thal der Macra herabkamen; die Flösserei lieferte von den Bergen herab Holz, das beim Haus- und Schiffbau Verwendung fand. Alsbald gelaugte auch der vortreffliche Marmor zu Ruf, der in der Nähe gebrochen, seit Caesar und mehr noch seit Augustus zu den Prachtbauten der Hauptstadt Rom mit Vorliebe verwendet wurde. Man führte das Material (zum Theil in Blöcken von beträchtlichem Umfang) zu Schiff nach den Häfen der Tibermündung, von da den Tiber aufwärts nach den Landungsstellen, wo kaiserliche Freigelassene die Aufsicht übernahmen ${ }^{4}$ ). Allerdings wurden neben dem Lunensisehen Marmor

Danach bildete eine Zeitlang die Macra Italiens Grenze, bis das cisalpinische Gallien mit dem Hauptlande vereinigt wurde.

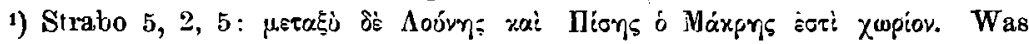
nur dann einen Sinn gibt, wenn der $\mathrm{H}$,fen von Luna, nemlich portus Veneris, unter Luna, hingegen unter dem Ort Macra ein Ankerplatz gemeint ist. Vgl. O. Cuntz über die Schifferstation Sabate am lacus Sabatinus. Jahreshefte des österr. archäol. Inst. II (1899) 83 f. - Auf einer Lyoner Inschrift Corp. inscr. Lat. XIII n. $1898=$ Henzen 5121 heisst es von einem jungen Mann: , sepellitus est Lunae Pisae in Tusci[a a]d flumen Macra \&, wozu Mommsens Bemerkungen in Corp. I'. p. 148 zu n. 539 zu vergleichen sind. Er versteht unter Luna Pisa die auf pisanischem Boden angelegte Colonie Luna. Ch. Müller zu Ptolem. 3, 1, 4, versucht eine noch andere Fm endation und Erklärung der Strabonischen Stelle, als Mommsen, ohne zu überzeugen.

9) Itiner. marit. ed. Wesseling p. 50l: a portu Pisano Pisis fluvius m. VIIII, a. Pisis Lune fluvius Macra m. XXX.

3) Vgl. Fiebiger, de classium Italicar. hist. p. 328, hiezu die beigegebene tabula 3. Bulletin épigraphique 1881 p. $231 \mathrm{f}$. Auf Corsica scheint die Station in Mariana (an der Ostküste der Insel gegenüber Elba) gewesen zu sein.

4) In Corp. insc. Lat. VI $8484 \mathrm{f}$. werden solche tabularii marmorum Lunensium aus der Zeit der Flavischen Kaiser genannt. Vgl. O. Hirschfeld, Unters. auf dem Gebiete der römischen Verwaltungsgesch. I 84; $87 \mathrm{f}$. Bruzza in den Annali dell' inst. 1870 p. 166 ff. Promis, dell' antica città di Luni p. 87. Ser- 
in der Glanzperiode der Kaiserzeit, die auch die technischen sowie die Verkehrsmittel imıner mehr ausnützte, z. B. für die Bauten auf dem Palatin noch Stein nud Marmorsorten aus den entlegensten Provinzen des Reiches, so aus Griechenland und Aegypten, verbraucht'1). Als aber in der zweiten Hälfıe des 3. Jahrhunderts Rom seine politische Bedeutung einzubüssen anfieng, beguügte man sich wieder mit dem Marmor von Luna, der auch zu Inschriftsteinen massenhafte Verwendung fand. Der dadurch bedingte Verkehr brachte es mit sich, dass Sprösslinge der Stadt Luna sich in Rom niederliessen und hier in angesehene Stelluugen gelangten. So stammte, wenn wir den Augabeu des römischen „l:ber pontificalis" für diese Zeit Glauben beimessen dürfen, einer der Bischöfe Roms im späteren dritten Jahrhundert, nämlich Eutychianus (275-283) aus Luna 2$)$. Die Notiz kann immerhin auf einen alten Bischofskittalog zurückgehen, dem die Notirung der Heimat wohl anstand. Die Stadt Luna erfreute sich dımals jedeufalls grosser Blüte; auf einer Inschrift vom J. $25 \check{5}$ wird sie als „splendida civitas Lunensis" bezeichnet. Abgesehen von Holz und von Mirmor (der nicht nur nach Rom und anderen Städten Italiens, sondern ebenso nach auswärts, z. B. nach Gallien ${ }^{3}$ ) gieng), exportirte sie auch Wein, was ausser Plinius in Pompeji gefundene Amphoren mit der Bezeichnung $L u(n e n s e)$ vet(us) durthun, ferner Käse, letzteren in Portionen von angestaunter Grösse ${ }^{4}$ ). Ein Amphitheater diente für die zeitgemässe Belustigung der Menge. Unter deu Innungen nahm die der Steinhauer in den Marmorbrü̈chen naturgemäss den ersten Rang ein. Von den erbgesessenen Fumilien ragte die wit dem Namen Titinnius

vius ad Aen. 8, 720 sagt vom Apollotempel des Augustus: de solido marmore quod allatum fuerat der portu Lunae.

1) Vgl. H. Jordan, Topographie der Stadt Rom I 18 ff.

2) Liber pontifical. ed. Mommsen p. 38 (= 241): Eutycianus, natione Tuscus, ex patre Marino, de civitate Luna . -- Cf. p. 32: , Lucius, natione Romanus (ex) patre Purphirio *, suscus, de civitate Lnca, ex patre Lucino * (p. Ch. 252-255). Die Heimatangaben sind nicht in allen Codices gleich genau. Andererseits führen die ältesten Hand*chriften des Liher pontif., wie die von Luca saec. VII, nach Etrurien. Vgl. Mommsen p. XII, p. XXIV.

3) Vgl. das Testament, eine, Lingoners aus dem Ende des 1. Jahrhunderts n. Chr., Wilmanns exempla n. $315=$ Bulletin épigraph. 1881 p. $22 \mathrm{ff}$ Er testirt: araq(ue) ponatur ante id aedific(ium) ex lapide Lunensi quam optimo senlpta quam optine, in qua ossa mea reponantur, claudaturq(ue) id aedific(ium) lapide Lunensi ita ut facile aperiri et denuo cludi possit. Anderes sei ex lapide transmarino herzustellen.

4) Plin. n. h. 11, 42 nennt die besten nach Rom kommenden Käsesorten: mixtoque Etruriae atque Liguriae confnio Luniensem magnitudine conspicunm, quippe et ad singula milia pondo premitur. 
hervor. Ein Mitglied derselben, L. Titinnius Glancus Lucretianus, bekleidete unter Nero mehrere staatliche Würden, die Männern von Ritterrang zukamen, so die eines Unterstatthilters (praefectus pro legato) der Balearischen Inseln ${ }^{1}$ ). Wir begegnen Inschriften durch den ganzen ager von Luna hin, z. B. auch bei Ceperana unfern der Mündung des Var in die Macra²), wo man sich ebenso der Villeggiatur hiugegeben haben wird, wis am Gestade des ligurischen Meeres, an dem wir den Dichter Persius Flaccus in dieser Situation nachweisen können ${ }^{3}$ ). Mit Luca und Pisae war Luna durch Strassen verbunden, deren Stationen die 1tinerare nemnen ${ }^{4}$ ). Der transapeoninische Verkehr führte nach Parma hinüber, wofür sich in erster Linie wie es scheint Luca interessirte, da es in Binnenlande gelegen war; es wird in den Itineraren als Endstation der Strasse anfgefiihrt ${ }^{5}$ ).

Zur See rivalisirte nit Luna schon im Alterthum Pisae, das im Jahre 398 als Ausgan rsspunkt der Expedition des Mascezel diente, durch die der gegen Stilicho gerichtete Aufstand Gildus in Africa niedergeschlagen werden sollte; die Fahrt gieng von Pisae rechts die Ligurische Küste, links die Etruskische, an Corsica vorbei nach Caralis, von wo aus nach Africa übergesetzt wurde. Auf der Insel Capraria hatte Mascezel gelandet, um einige Mönche mitzuuehmen, von deren Grebet er zu profitiren hoffte ${ }^{6}$ ). Achtzehn Jahre später fuhr ein grimmiger Hasser Stilicho's diese Küste entlang, der aus Rom nach seiner gallischen Heimat zurückkehreude Rutilius Nanıatianus (416 n. Chr.). Wir verdanken ihm eine gute Schilderung der Küstengegend: nachdem er die Bucht von .Populonia, dessen Altstadt schon sehr heruutergekommen

1) Wilmanns $1619=$ Corp. XI 1331 : Widmung für die diva Poppaea Angusta und den K. Nero a. 66 p. Ch. (bei Cecina nahe Carrara). Vgl. Corp. XI 1347-50.

2) Corp. XI p. 260.

9) Vgl. Persius Sat. VI v. 6 f. mihi nunc Ligus ora intepet hibernatque menm mare, qua latus ingens dant scopuli et multa litus se valle receptat. Persius stammte aus einer Rittcrfamilie von Volaterra, war aber auch bei Luna begütert. Hier schrieb er diese Satura.

4) So p. 289: a Luca lune m. p. XXXIII. Ferner: Pisa - fossae Papirianae - (ad tabernas frigidas) - Luna. So im Itin. Ant. p. 293 resp. anf der Peutinger'schen Tafel. Die nächste Station in der Richtung anf Genua, $12 \mathrm{~m} . \mathbf{p}$. von Luna entfernt, hiess Boaceas, nach einem Seitenfluss der Marcra, wahrscheinlich dem jetzigen Var. Die Station wird demnach unweit des Zusammenflusses von Macra und Var, beim heutigen Vezzano anzusetzen sein.

5) Itin. Anton. p. 234: a Parma Lucam m. p. C (runde Zahl!).

6) Claudian. de bello Gildonico $\nabla .482 \mathrm{ff}$; vgl. Oro-ii contra paganos VII 36 : Mascezel - Caprariam insulam adiit, unde secum sanctos servos dei aliquot permotos precibus suis sunpsit. Augustinus correspondirte von Africa aus mit dem Abt von Capraria. Edit. Migne 2, 187. 
war, hinter sich hatte, liegen die Inseln Corsica, Capraria, Gorgon in seinem Gesichtskreis (letztere der Aufenthaltsort weltscheuer Eremiten). An dent Uferorte von Volaterra vorbei erreicht er den Hafen von Pisae, besucht Pisae selbst (wo im Alterthum die Flüsse Arnus und Auser, d. i. Serchio sich vereinigten) und setzt dann die Fahrt fort. Die schimmernden Mauern von Luna kommen in Sicht1) und die marmorberühmten Berge.

Un diese Zeit muss Luna seinen eigenen Bischof erhalten haben, da die kirchliche Organisation für Italien im Laufe des 5. Jahrhuuderts sich vollendete. Wir sehen in der Folge Bischöfe von Luna an den römischen Synoden von 465, 501, 502 sich betheiligen, auch mit den Päpsten Correspondenz pflegen ${ }^{2}$ ).

Weiter ist von Luna in dieser Zêit nicht die Rede; so viel ist klar, dass es der Tuscia annonaria zugerechnet wurde und dass dies auch nach dem Sturze der Gothenherrschaft der Fall war. Bemerkt zu werden verdient, dass die Bischöfe von Luna in kirchlicher Hinsicht weit mehr herrortreten, als die von Pisae oder Luca, welche auf keiner der gevannten Synoden erschienen ${ }^{3}$ ). Als Narses im J. 552 die Unterwerfung Itulieus vollendete, höreu wir, dass neben den Bewohnern der andereu Küstenstädte Tusciens: Centumcellae, Volaterrae, Pisae auch die von Luna sich ergaben ${ }^{4}$ ). Hingegen leisteten die Gothen in Luca noch drei Monate lang Widerstand.

Es hatte sich in Laufe des gothisch-byzantinischen Krieges eine Situation entwickelt, die für die politische Gestaltung der Apenninenhalbinsel auf Jahrhunderte hinaus entscheidend sein sollte. Nach dem Verluste Ravenna's hatten die Gothen wieder Ticinum zu ihrer Hauptstadt erhoben (wie einst Theoderich, ehe er Ravenna einnahm), von wo aus ebenso die transalpinen Beriehungen gepllegt wie der Sitz des Feindes Ravenna stetig im Auge behalten werden könte.

1) Rutilius Namat. de reditu suo II, $63 \mathrm{f}$. Advehimur celeri candentia moenia lapsu Nominis est anctor sole corusca soror. Vgl. Reumont's Commentar: ${ }_{\supset}$ Des Claudius Rutilius Namatianus Heimkebr übersefzt und erläutert von Itasins lemniacus (Berlin 1872) S. 188 ff. Vortreffliche Ausführungen über die Küstengegenden. Er erwähnt S. 174 den Aufenthalt Augustins zu Gorgon auf der Fahrt von Africa nach Luna.

2) Vgl. den Index zu Cassiodor's Variae ed. Mommsen. - Am 16. April 556 schreibt Papst Pelagius I den 7 Bischöfen ,per Tusciam annonariam*. Darunter sind die von Volaterra, Luna, Florentia. Vgl. Davidsohn, Gesch. von Florenz I 56 Anm. 1.

3) Vgl. den Index zu Mommsen Cassiodorausgabe 1. c.

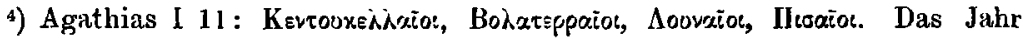
vorher (551) batten die Gothen von hier aus auch Corsica besetzt. 
Ticinum stand mit Tuscien über die Apenninenstrasse, die von Parma nach Luca führte, in Verbindung. Dieser Strasse hatte sich Narses bemächtigt ${ }^{1}$ ); während Luca belagert wurde, erwarteten bei Parma die Heruler des byzantinischen Heeres den Angriff der die Gothen unterstützenden Alemannen. Als sie eine Schlappe erlitten, kamen die Operationen diesseits und jenseits des Apennin eine zeitlang nicht zum Klappen; bis endlich Luca capitulirte ${ }^{2}$.

Die Herrschaft der Byzantiner über gauz Italien war nicht von Daver. Die germanischen Hilfsvölker rebellirten und wenn Narses auch der Heruler Meister wurde, so waren andererseits die Langobarden, als sie 569 unter Alboin in Italien einrückten, überall siegreich. Und sie zeigten, dass sie unter byzantinischer Führung die strategisch in Betracht kommenden Positionen wohl kennen gelernt hatten. Sie setzten sich in Verona fest und machten sich sofort an die Belagerung von Ticinum; während diese sich noch hinzog, überstiegen sie auch den Apeunin und plünderten in Tuscien ${ }^{3}$ ). Dann wurde Ticinum ihre Königstadt, für Tuscien aber Luca der Hauptsitz der langobardischen Machtstellung, da Florenz einem Angriff von Ravenna und Faventia her zu leicht ausgesetzt war. Man richtete sich durchius auf dem Kriegsfusse tin.

Da man keine Flotte hatte, blieben die Küstenstriche im Machtbereich der Byzantiner, nicht nur längs des adriatischen Meeres in Venetien, sondern auch an der ligurisch-tuscischen „Maritima“, von Ventimilia angefangen bis nach Luna; selbst Pisa scheint noch durch Jahrzehute von den Langobarden unabhängig gewesen zu sein ${ }^{4}$ ),

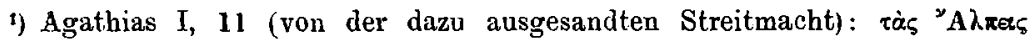

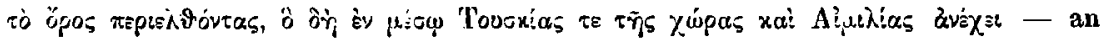
den Po.

9) Agnellns ad a. 553 (Auct. ant. I p. 335): et (Narses) venit Lucam; expulit inde Gothos mense Septembri. Hiezu Agathias I, 12-19. Hartmann, Das ital. Königreich I, 339 würdigt das strategisch-topographische Moment ebensowenig, wie Davidsohn, Gesch. von Floreuz, während doch Florenz damals seinen Vorrang in Tuscien an Luca zu verlieren anfieng.

3) Agnellus l. c. I, 336: post vero depraedata a Langobardis Tuscia obsiderunt Ticinum. (Befestigungsarbeiten in Ravenna), post haec vero exierunt Langobardi et transierunt 'lusciam usque Romam. Hiezu Paul, dıac. Il, 26: Alboin, eiectis militibus, invasit omnia usque ad Tusciam, praeter Romam et Ravennam vel aliqua castra, quae erant in maris litore constituta.

4) Vgl. Gregorii reg. XIII, 36 (a. 603). Der Papst schreibt an den Exarchen Smaragdus (der im Kriege mit den Langobarden stand), er habe an die Pisaner geschir:kt: drumones eorum iam parati ad egrediendum nuntiati sunt. Wie alich Hartmann anmerkt, müssten danach die Pisaner damals noch unter byzantinischer Herrschaft gestanden haben. - Bei Georgius Cyprius wird Pisa nicht erwähnt. 
während auf den kleinen Inselv, z. B. Elba, die Flüchtlinge aus dem Binnenlande sich auhäuften. Wie der Erzbischof von Mailand nach Genua, so flüchtete der Clerus von Faesulae nach Luna ${ }^{1}$ ), suchte der Bischof von Populouium auf Elba Schutz ${ }^{2}$, da die Lungubarden gegen die römischen Institntionen ebenso durchgreifend vorgieng $n$, wie die Gothen während ihrer letaten Kämpfe, dinn die ihnen zu Hilfe kommenden Alemaunen und Franken. Der Schutz, den die byzantinische Flotte den italischen Küsten im Westmeer bieten konnte, hieng übrigens wesentlich ab von der Machtstellung des Reiches in den ufricanischen Provinzen, zu denen auch Sardinien (und Corsičl) gehörten. Als an Ende des 7. Jahrhunderts das africanische Festland in die Hände der Araber fiel, hielten die Byzantiner gleichwohl noch einige Positionen, z. B. an der mauretanischen Küste, auch auf Sardinien ${ }^{3}$ ). Aber von der ligurisch-tuscischen Maritima konnten sie die langobardische Eroberung schon früher nicht mehr abwehren. Um das J. 640 n. Chr. nahm der Langobardenkönig Rothari die hiesigen Städte ein, angefangen vom Tuscischen Luna namentlich Genua, Saona, Varicotti (bei Noli), Albingaunum ${ }^{4}$ ). Der labile Zustand der byzantinischen Herrschaft an diesen Küsten hatte demnach beiläufig 70 Jahre gedauert, In dieser Zeit war Luna fortdauernd mit der Stadt Rom in Verkehr gestanden, wie wir aus der ziemlich lebhaften Correspondenz des Papstes Gregor I. mit dem Bischof Venantius von Luna ersehen; auch die $\mathrm{Zn}$ stände in Stadt und Gebiet lernen wir daraus kennen. Man spricht von der "civitas" und vom "territorium Lunense", auch von dem "Lunenses partes", vom „portus Veneris", d. i. dem Hafen von Luna. Die „iudices“, welche seit der Aufrichtung der byzantinischen Herrsehaft in Function sind, finden wir in voller Thätigkeit. Die Gesetze des

1) Gregorii reg. IX, 143.

2) Gregorii M. dial. IIL, 11. Vgl. Gregor. reg. I, 15, wonach der Bischof von Rusellae beauftragt wird, auch die Diöcese von Populonium zu versehen. Die Insel Elba unterstand dem Bischof von Populonium (später Massa maritima). Auch die Beziehungen $2 u$ Sardinien und Corsica waren (wie im Alterthum, vgl. Lir. 39, 30; Virgil. Aen. 10, 172 ff., im Uebrigen Corp. XI p. 412) von hier aus rege.

s) VgI. Gelzer, Die Genesis der byzantinischen 'Themenverfassung S. 30.

4) Paul. diac. IV 45: Romanorum civitates ab urbe Tusciae Lunensi universas quae in litore maris sitae sunt usque ad Francorum fines cepit. Vgl. Origo gent. Langob. 9. Fredegar IV, 71: Chrotarius cum exercito Genava maretema, Albingano, Varjcotti, Saona, Ubitergio et Lune civitates litore mares de imperio auferens, vastat, rumpit, incendio concremans; populum derepit, spoliat et captivitate condemnat. Murus civitatibus supscriptis usque ad fundamento distruens, vicus has civitates nomenare praecepit. 
byzantinischen Staates werden $v(\cdots n$ ihnen missbräuchlich vielleicht minder streng gehandhabt, aber dufür von der geistlichen 0 ')rigkeit eingeschürft, so z. B. bezüglich der christlithen Dienstboten und Colonen jüdischer Besitzer; galt das Dienstverhältnis wegen der Gefuhr für den Glauben als unzuläs.irr ${ }^{1}$ ), so unterlag das Ziusen der Coloni wenigstens einem solchen Anstaude nicht; es bi dete nach wie vor lie Grundlage der Agrarverfassung. Die Bodentleeilungr der rönischen Zeit, wonach die einzelnen "fundi“ in Evidenz gehalten werden, finden wir grlegentlich der Ausstattnng eines Klosters, das Bischof Venantius stiftete, erwïhnt; ebenso die Zusimmenlegung von „fundi“, wie wir sie aus den Veleiater Alimentartafeln kennen ${ }^{2}$ ). Das Gebiet der Stadt Luna die Macr, eine Strecke aufwärts ist iutact, man kanı ausserhalb der Mauern Rechtsgeschäfte, die sich auf Läudereien bezichen, abschliessen. Ls herrscht ein "modus vivendi“, der auch von Lucia her nicht in Frage gestellt ist; hier waltete bis 578 der Bischof Frigidianus, der im Rufe der Heiligkeit staud und von den Lucchesen auch in der Folgezeit immer hochgehalten wurde. Papst Gregor erwähıt in seinen Dialogen eine wunderthätige Handlung, die dem Frigiclianus zugeschriebeu wurde, nachdem ein Ausbruch des Auser (d. i. des Serchii) grossen Schaden verursacht hatte. Für diese Erzühlung macht Gregor den Bischof Venantius von Luna als Gewährsmann namhaft ${ }^{3}$. Und wie Frigidianus in Luca so ward des Venintius Nachfolger Basilius in Luna als Heiliger und Patron der Kathedrule verehrt; was doch auch beweist, dass man dieser Epoche nicht nur einen zerstörenden, sonderu auch einen constituirenden Charikter zuschrieb. Luna wird in den byzantinischen Proviuciallisten regelmässig aufgefülırt, so bei Georgius Cyprius ${ }^{4}$ ). so beim Geographen von Ravenna ${ }^{5}$ ). Aus der eiuen oder anderen Grab-

1) Gregor. reg. IV, 23. Papst Gregor an den Bischof Venantins : nt secundum piissimarum legum tramitem nulli Judaco liceat Christınum mancipium in suo retinere dominio. Sed si qui penes eos inveniuntur, libertas eis tuitionis auxilio ex legum sanctione servetur.

2) Gregor. reg. VIII, 5: fundum Faborianum et Lumbricata in integrum constitutum teritorio Lunensi miliario ab urbe plus minus secundo iuxta fluvium Macram et boves paria II tantum, gestisque munıcipalibus allegatis . . . .

8) Dialog. 1II, 9. Bisthof Venantius war im Jahr 593, als Gregor die Dialoge abfasste, seiner Ordination wegen in Rom. Vgl. die Anm. Ewalds zu reg. IV, 21.

4) Georgius Cyprius verzeichnet unter den Städten dex Urbicaria: Vinti-

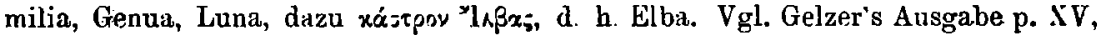
XIX, XXVE und 85. Ob anch der Purtus Veneris genannt ist, bleibt in Folge der mangelhaften Textgestaltung zweifelhaft.

5) Geogr. Ravennas 249, 5: provincia maritima Italorum, quae dicitur Lunensis, et Vigintimilii et ceterarum civitatum. Aehnlich zählt Guido Pisanus 
schrift, die sich aus dieser Zuit erhalten hat, geht hervor, dass nach den in Byzanz regierenden Kaisern datirt wird ${ }^{1}$ ). Da zu der dem Kaiser Phocas im J. 608 auf dem Forum zu Rom errichteten Säule Marmor von Luna verwendet ist'2), kann es keinem Zweifel unterliegen, dass in den Brüchen daselbst nach wie vor gearbeitet und das Material nach Rom geliefert wurde. Von den oberen Behörden der "Maritıma“ ist weiter nicht die Rede; wir erfahren aus den Schriften des Papstes Gregor nur, dass die Mailäuder staatlichen und kirchlichen Würdenträger vor den Langobarden nach Genua eutflohen waren, wo sie amtirten und mit Luna Verkehr unterhielten ${ }^{3}$ ).

Indem Bischot Venantius in Auftrage des Papstes daran gieng die verfallene Kirchenzucht wieder herzustellen, erstreckte er seine Wirksamkeit nicht nur auf den näher gelegenen Portus Veneris ${ }^{4}$ ), sondern auch hinüber zu den Klosteransiedlungen auf den Inseln Capraria und Gorgona 5 ).

Auch über Corsica erstreckt sich die Fürsorge des Papstes, der mit den Bischöfen der Insel, mit dem Exarchen von Africa (dem sie unterstand), desgleichen mit dem Hofe von Constantinopel correspondirte; nicht nur wegen des Seelenheils sondern tbenso wegen irdis her Bedürfnisse. Bereits machten die langobardischen Eınflüsse auch auf

p. 504, 10 unter den Provinzen auf: Octava decima Vintimilia Ripariolum Linensis quae et maritima. Bei Gregor. reg. IV, 20 sind erwähnt die Berichte quorundam de Lunensium partibus venientium.

1) Corp. XI 1409 (vom J. 573-574): ,imp. d(o)m(i)n(o) Justin[0 ....] $\operatorname{ann}(0)$ VIIL*.

2) Vgl. Jordan, Topographie der Stadt Rom im Alterthum I, 29.

3) Gregor schreibt reg. IX, 103 nach Genua an den obersten Beamten: Joannes vir magniticus qui praefecturae illic vices acturus advenit. $\nabla$ gl. hiezu die Anm Hartmanns. Diehl, Études sur l'administrat. byz. p. 30, 45, 161. In Gregors dialog. IV 53 ist von einem in Genua verstorbenen Valentinus, ecclesiae Mediolanensis detensor, die Rede, wofür B. Venantius von Luna als Gewährsmann genannt wird. Der Papst empfiehlt dem in Genua sitzenden Bischof Constantius von Mailand den Venantius von Luna in Hinsicht auf die einzuleitende Reformation der klerikalen Zucht, woza die Beihilfe des Constantius sich als nöthig erweist. Reg. IV 22. Vgl. auch ibid. XIIL 33 (a. 603): B. Venantius als Schiedsrjchter zwisthen B. Deusdedit von Mailand und einem diesem unterworfenen Bischofe, dessen Sitz nicht genannt ist.

4) Gregorii 11 . reg. V, 17; V, 181 .

s). Vgl. Giregor. reg. V, 5. An den Bischof Venantius: ut in Gorgonam insulam vectus, Saturninum expresbyterum, si post lapsum procurare sacra perget, excommunicet. V, 17 (in der Angelegenleit desselben expresbyter): eum in insula Gorgona atque Capraria sollicitudinera de monasteriis gerere permittimus. Deber Gorgona auch reg. I, 50. Auch die Insel Monte Christo wird als Sitz von Mönchen erwähnt $1,49$. 
Corsica sich geltend, da die Grundbesitzer die Steverlast unter byzantinischer Herrschaft immer drückender empfanden; im J. 595 versichert Gregor, dass viele derselben ihre Heiunat verliessen, um auf langobardisches Gebiet zu übersiedeln ${ }^{1}$ ). Die Langobarden ihrerseits setzten zwar wiederholt nach der Insel über um sie zu plündern, aber eine danernde Occupation hat erst zu Anfang des 8. Jahrhunderts stąttgefunden ${ }^{2}$ ).

Vielniehr stellte sich, nachdem die ersten harten Massregeln der langobardischen Herrscher überwunden waren, überall ein ruhigerer Zustand her. Der Verlsehr von Luna und Luca über den "Mons Bardonis", wie er jetzt genannt wurde, kam wieder in Gang, für die Langobarden wie für die Römer, da dieser Weg über Parma links nach Pavia, rechts nach den unter byzantinischer Herrschaft sich befindlichen Städten führte. Nur wenn Feindseligkeiten eintraten, wurde der Verkehr unterbrochen und die Reisenden abgefangen, bis zum nächsten Friedensschluss ${ }^{3}$ ).

Da die byzantinischen Städte an der tuscisch-ligurischen Maritima von denen im Polande durch die langobardischen Occupationen auseinaudergerissen waren, so musste es von Bedeutung sein, die Sicherheit des internationalen Verkehres, die Verweudbarkeit der Strassen, z. B. für die Langobarden von Pavia über Ravenna nach Benevent, für die Byzantiner von Luna nach der Aemilia und von da nach dem Venetianischen vertragsmässig festzustellen. Das dürfte, vielleicht zur Zeit, da Kaiser Phacas im J. 605 den Frieden mit den Langobarden abschloss ${ }^{4}$ ) bezüglich der Strasse von Luna über den Mons Bardonis nach Parma (von da weiter nach Regium, Mantua, Mons Silicis, die

1) Reg. V, 38: Corsica vero insula tanta nimietate exigentium et gravamine premitur exactionum, ut ipsi qui in illa sunt eadem quae exiguntur complere vix filios suos vendendo snfficiant. Unde fit, ut derelicta pia republica posses. sores eiusdem insulae ad nefandissimam Langobardoram gentem coguntur effugere. Vgl. Dore (1894) S. 20 ; f.

2) Vgl. Dove, de Sardinia insula p. $23 \mathrm{f}$.

3) Vgl. Paul. diac. IV, 20: capta est filia regis Agilulfi cum viro suo Gudescalco nomine de civitate Parmensi ab exercitu Gallicani patricii, et ad urbem Ravennatium sunt deduc1i. Das ergab einen Kriegszustand ( $V$, 28). Agilulf nimmt Mantua ein, auch Brexillum. Darauf gibt der Patricius Smaragdus nach und es wird im J. 605 Frieden geschlossen. Filia $v \in$ ro regis mox a Kavenna Parmam rediit.

4) Vgl. die Inschrift der Phocassäule in Rom Corp. insc. Lat. VI 1200: pro quiete procurata Ital(iae) ac conservata libertate. Der liber pontif. ed. Mommsen p. 163. meldet in der Vita des Papstes Sabinianus (Nachfolger Gregors d. Gr. 604-606): tunc facta pace cum gente Langobardorum. Uebrigens werden wiederholte Friedensschlüsse erwähnt, z. B. Paul. diac. IV 40 zum J. 612. 
Bis zum letzten Kriege byzantinisch gewesen waren) thatsächlich statuirt worden sein. Darauf basirt nach meiner Ansicht das „coufinium", das im 8. Jahrhundert bei den Verhandlungen der Päpste nit den Frankenherrschern für die Romana re.publica in Anspruch genommen worden ist ${ }^{1}$ ). Eine "Grenzlinie“ war die angegebene nur in dem Sinne, wie Strassenrouten es in dieser Zeit auch sonst waren. Sie wurde römischerseits von Luna, langobardischerseits von Luca aus begangen. Sie hat in der ersten Hälfte des 8. Jahrhunderts, wo die nach Rom reisendın Nordländer sie vie! benutzten, ihre weitere Ausgestaltung durch Aulegung von Hospizen u. s. w. erhalten ${ }^{2}$ ); woran wie auf der einen Seite Purma, so uuf der anderen Luna in erster Liuie iuteressirt war. Daher stellten sich anch gruanere Itinerarangaben fest, während dis Alterthum solche noch nicht gekannt hatte.

Obwohl die Luuenser vı n König Rothari seiner Herrschaft unterworfen worden waren, belielten jene Abmachungen über den Apennive «weg gleichwohl ihren Wert, ja Luva muss sich jetzt noch weiter entwickelt und namentlich unter langobardischer Aegide auch der Anschluss der Insel Corsica an die tuscisch-ligurische Küstenlandsc haft sich vollzogen haben ${ }^{3}$ ). Lnd weil Luna damals (wie früher Populonium, später Pisa) hier die führencle Stellung einnahm, wird dies ein Anschluss Corsica's an das Lunensische gewesen sein, was in der zweiten Hälfte des 8. Jahrhunderts in don ,promissiones“ der Frankenkönige zum Ausiruck komut. Die Lunenser griffen nach allen Seiten um sich, indem sie die sich kieuzenden Jnteressen der Nachbaren, ganz wie auf der auderen Seite des Neeres Vencdig, zu ihren Gunstrn ausnïtzten. Denn mit dem hyzantinisch-römischen Theile von Italien fühlten sie sich trotz ihrır Unterwerfung gleichwohl wie früher verbunlen. Wir hören, dass sie im J. 727 an einem Pronunciumento

1) Nach der bekannten Stelle in der Vita IIadriani I papae (I p. 498 ed. Ducherne) üler dis, confinium : : a Lunis (cum insula Corsica), deinde in Suriano, deinde in monte Barlonis, id est in V'erceto, deinde in Parma, deinde in Regio, exinde in Mantua atque Monte Sili is. - Dır Besitz von Mantua, Purma, Reggio hatte in den Jahren unmittell,ar vor 605 wiederholt gewechselt. Mons Silisis zam in Folge der Zerstörung von Patavium (Panl. diac. IV, 23) zu grösserer Bed‘ułung, die für jene (iegenden durch Jahrhunderte sich erhielt. Vgl. Biesslau, Jahrb. Konrad's II. Bu: I, 4:8.

2) Prul. diac. V, 27. VI, 58. Vgl. im Allgemeinen J. Zettinger, Die Berichte übcr Romplilger aus dem Frankenlande bis zum J. 800. Röm. Quartalschrift. 11. Supplementheft (190:0).

3) Vgl. Dove, Corsiı a und Sardinien in den Schenkungen an die Püpste. Sitzungster. der Nünchener Akad. 1*94 S. 209. Papst Hadriun I im J. 778 über die auf Corsica von den Langobarden entrissenen Patrimonien: per annorum spatia abstulta atque ablata sunt. 
gegen den bilderstürmenden Kaiser Leo sich betheiligten (dessen Flotte drei Jahre später auf der Adria eiven Unfall erlitt). Der Anschlag gieng im römischen Tuscien ron Mauturianum (westlich rom Lago di Bracciano) aus und fand auch in Biera Anhänger ${ }^{1}$ ); da aber der Papst dagegen war und den byzantiuischen Behörden mit seiner Autorität beistand, konnte der Anstifter in Manturianum getödtet und die Meuterei unterdrückt werden. Die kirchlichen Kreise in Luna standen zu dem Papste in eng-tem Einvernehmen, so dass die Bischöfe dieser Stadt anch jetzt an den römischen Synoden sich eifriger betheiligten, als die anderen Bischöfe des nördlichen Tuscien ${ }^{2}$ ). Offenbar war der Seeverkehr bequemer als der Landweg, ganz abgesehen davon, dass man auf diesem eiuer Art Passierschein bedurfte, um durchzukommen. Seitdem die Frankenherrscher mit der römischen Kirche conspirirten, wurden die Langobardenkönige misstrauischer und überwachten den Strassenverkehr.

Als dann die Leiter der römischen Kirche bei den Königen Pippin und Karl die entscheidenden Schritte Namens der Romana respublica thaten, wurde bei Festsetzung des alten Besitzstandes auch Luna nicht vergessen, vielmehr zusammen mit Corsica und dem Apenninenwege über den Mons Bardonis in die Interessensphäre des künftigen Kirchenstuates miteinbezogen ${ }^{3}$ ); indem man die Route von Luna bis Monselice als eine

1) Vgl. den liber pontifical. I p. 408: venit in partibus Tusciae in castrum Manturianense quidam seductor, Tilierius nomine, cui cognomen erat Petasius, qui sibi regnum Kumani inpeiii usurpare conabatur, leviores quoque decipiens, ita ut Manturianenses, Lunenses atque Blerani ei sacramenta praestitissent. Manturianum (dessen Bischof auf den römischen Synoden dieses Jahrhunderts erscheinf) ist das auch in den Privılegien der rönischen Kirche genannte Monteranno, wie Duchesne p. 483 n. 43 (gegen p. 413 n. 41) bemerkt. Was er an letzterem Orte über die Lunenses sagt, ist zu berichtigen, die Theilnahme derselben an jenem Pronunciamento zu erklären. Vgl. auch Bury, a history of the later Roman Empire II p. $4+3 \mathrm{f}$.

2) So unter P. Stefan IIL (768-7i2). Liber pontjf. I p. 474. Neben dem Bischof von Luna erscheint auf der römischen Synode von 769 der Bischof von Populonium. Aus dem langobardischen Tuscien sind sonst nm die Bischöfe von Castrum (bei Acquapendente), Tuscana (Toscanella), Balneoregis (Bagnorea) da. - Im J. 826 war Bischof Bertoald von Luna anf der von P. Eugen II abgehaltenen römischen Synode anwesend. Vgl. Monum. German. Leg. II B p. 14.

8) V'gl. Sickel, Das Privileg Ot·o I. für die röm. Kirche S. 135; Dove (1894) S. 202. Beide denken an eine kartographische Darstellung (mit Itinerarangaben, nach Art der Peutingerschen Tafel). Dazu wäre zu vergleichen Mommsen über die Ravennatische Kosmographie S. 96 ft.: die Karte des Kosmograpben, die in den karolingischen Klosterschulen gebrauchten Karten, die Itinerarien als Abschriften der Karte. 
Grenzlinie hinstellte, die das Langobardenreich zwischen den Franken und dem Papste theilen sollte ${ }^{1}$ ). War doch in der Zeit zwischen 754 und 774 alles schwankend; selbst das tuscische Herzogthum in Luca zeigte sich unter Desiderius geneigt, den Schutz des Papstes zu acceptiren und dafür alles zu versprechen, was man wollte. Wenn der Köuigszins, den das Langobardische Tuscien früler nach Pavia gezahlt hatte, genäss lem Privileg Ludwig's des Frommen vom J. 817 nunmehr nach Rom zu leisten war, so wird dies wohl mit Recht als ein Compromiss zwischen den 754 und 774 erhobenen Ansprüchen des Papstes und den fränkischen Langobardenherrschern angesehen.

Da die Durchführuug jener ausschweifeuden „Verheissungen“ von Karl d. Gr. sistirt und durch concretere Abmachungen ersetzt wurde, haben jene für Luna zunächst keive praktischen Folgen gehabt. Namentlich bei den Verhandlungen vom J. 787 spielt Luna keine Rolle, während Rusellae, Populonium und andere Orte des langobardischen Tuscien damals dem Papste eiugeräumt wurden. Ebensowenig wurde über Luca verhaudelt ${ }^{2}$ ). In Bezug auf (orsica wird von P. Hadrian 778 die Rückgabe der dahier weggenommenen Patrimonien der römischen Kirche verlangt, erst im J. 808 von $P$. Leo vielleicht weitergehenden Ansprüchen Ausdruck gegeben. Auch hier ohue durchzudringen; und bald erhoben sich für Italien und das Gesammtreich ganz undere Sorgen ${ }^{3}$ ). Um diese Zeit begannen vämlich die Anfälle der Saracenen auf die italischen Küsten grössere Dımensionen anzunehmen, da die Schutzwehr, welche früher die byzantinische Flotte, wenigstens theilweise, geboten hatte, seit dem Abfall Italiens nicht mehr vorhanden war. Im J. 806 wurde Corsica heingesucht, wogegen der Graf von Genua ent-

I) So Kehr, Histor. Zeitsch. 70, 385 ff. vgl. Göttinger Gel. Anz. 1895 S. 694 ; was Duchesne, les premiers temps de l'état pontifical (754-107.3), Paris 1878, p. 71 als erwägenswert bezeichnet. Auch Dove stimmt bei. Hingegen sind die Ausfïhrungen von Sackur (Mitth. d. österr. In-t. XIX S. 55 ff.) wenig glücklich. Der Pass von La Cisa ist in der Zeit zwischen 570 und 754 niemals Keichsgrenze gewesen, da vielmehr Luca zu den ersten Occupationen der Langobarden gehörte. Und eine Festungslinie war hier auch nicht. - Militärisch besetzt scheint von den Byzantinern um $600 \mathrm{n}$. Chr. hingegen die Position von Bismantua gewesen zu sein (vgl. Gelzer, Georgii Cyprii desc. p. 98 ad 623 c. Hiezu mein, Bobbio * S. 532 Anm.). Wohl auch Ferronianum (vgl. Gelzer, l. c.), d. i. Frignano, also. die östlicher liegenden Uebergänge, wie auch die via Flaminia.

2) Vg]. die Reichstheilung vom J. 806. Das westliche Oberitalien „una cum ducata Toscano usque ad mare australe et usque ad Provinciam " wird beisamménbehalten. - Nur Benedictus a S. Andrea redet auch später noch von ganz Tuscien. Forschungen z. D. Ge-ch. XIV, $427 \mathrm{f}$.

3) Neberbei bemerkt, wurde 801 der von Harun al Raschid an Kaiser Karl geschenkte Elefant in Portus Veneris gelandet. Einhardi ann. ad. a. 
sendet, und als dieser im Kampfe fiel, weiter gehende Rüstungen angestellt wurden, aber ohne für die nächsten Jahre wiederholte Katastrophen hintanhalten zu können ${ }^{1)}$ Erst $828 \mathrm{kam}$ es zu eivem kühnen Unternehmen von Tuscien aus, indem der Graf Bonifacius (von Luca), dem eine umfassendere Gewalt und namentlich auch der Schutz von Corsica anvertraut war, mit seinem Bruder und einigen tuscischen Grafen die "befreundeten" Sardinier zur Couperation heranzog. Es wurde ein Streifzug nach Africa in die Gegend der alten Städte Utica und Carthago unternommen ${ }^{2}$ ). Auch in den folgenden Jahren bleibt dem tuscischen "Markgrafen" der Schutz Cursicu's speciell anvertraut ${ }^{3}$ ), während die Sarden sich selbst zu wehren wissen.

Im Allgemeinen dauerte die maritime Ohnmacht Italiens trotzdem fort und es wurde davon neben anderen Seestädten namentlich auch Luna schwer betroffen, wo im Jahre 849 Mauren und Saracenen landeten und plünderten ${ }^{4}$ ). Als Kaiser Ludwig im Jahre 866 neue Rüstungen gegen die Saracenen anordnete, wubei die Aushebungsbezirke bestimmt wurden, finden wir (neben Pisa und Luca) auch Pistoria und Luna einem eigenen Missus unterstellt ${ }^{5}$ ).

Bereits hatten sich zu den Gegnern die seetüchtigen Normannen gesellt. Schon im J. 825 drangen diese den Arnus herauf raubend bis Fuesulae vor ${ }^{6}$ ), im J. 860 kamen sie wieder, von der Rhonemün-

1) Vgl. Mühlbacher, Reg. ${ }^{2}$ n. 422 b ad a. 806; n. 428 a ad a. 807 : die Mauren in einem Hafen Corsicas geschlagen. Weitere Seerüstungen im J. 808. Im J. 809 wird eine Stadt Corsicas ron spanischen Mauren geplündert (n. $4+1$ a): im J. 810 Corsica, ohne Besatzung, fast ganz verheert; 813 fängt der (iraf von Ampurias bei der Insel Majorca acht Schiffe einer maurischen Flotte ab, die mit Beute beladen aus Corsica heimkehrt und befreit über ein halbes Tausend gefangener Corsen - woraus erhellt, dass es sich wie einst im Alterthum so auch jetzt: wieder um Sklavenjagden bandelte. Im J. 825 gab ein Capitulare Lothar's I. Anordnungen für dje Grafen, die das Aufgebot nach Corsica zu führen haben. Mühlbacher22 1123.

2) Einhardi Ann. ad a. 828. V. Hlud. c. 42. Vgl. Mühlbacher Reg. $852 \mathrm{e}$. Dore a. a. 0. 218.

3) So warnt im J. 846 Adelvertus, tutor Corsicanae ineulae (Adalbert I., Markgraf von Tuscien, Sobn des Bonifacius) den Papst Sergins II. vor dem Ueberfall durch eine africanische Flotte. Vita Sergii II. c. 44. Vgl. Dove, Sirzungsber. a. a. $0.218 \mathrm{f}$. Wenige Jahre nachher $(852$ ) $)$ siedelt der Papst Leo IV. mit Bewilligung der Kaiser Lothar und Ludwig Corsen, welche s ob timoren Saracenorum * geflüchtet sind, in der Hafenstadt Portus an. Jafléz n. 2617. Vgl. Dove (1894) S. $219 \mathrm{f}$.

4) Prudentii Ann. ad a. 849: Mauri et Saraceni Lunam, Italiae civ tatem, adpraedantes, nullo obsistente maritima omnia usque ad Provinciam devastant.

5) Mon. Germ. Leg. 1505 : Pistoris et Lunis.

5) So Davidsohn, Gesch. von Florenz I, $81 \mathrm{f}$. Forschungen I, 27.

Jittbeilungen XXII. 
dung her, und nahmen Pisa ein sowie andere Städte, die geplündert und verwüstet wurden 1 ).

Unter diesen ,anderen Städten" scheint sich auch Luna befunden zu haben, wenngleich die Erzählung, die darüber bei den Normannen umlief mit mancherlei fabelhaften Zügen versetzt ist. Es wird ein Ueberfall der Stadt Luna geschildert, in der die Normannen dadurch ein furchtbares Blutbad anrichten, dass ihr Anführer sich erst vom Bischof zum Schein taufen, daun wie ein Verstorbener auf der Bahre in die Kathedrule bringen lässt, um plötzlich wieder lebendig zu werden. Luna soll von ihnen, im Wahn es sei Rom, geplündert und zerstört worden $\operatorname{sein}^{2}$ ).

Das Ereignis hat noch vach Jahrhunderten in den Ueberlieferungen der Normannen und weiterhin in der nordischen Heldensage überhaupt eive Rolle gespielt ${ }^{3}$ ). Für Luna bedingte diese Katastrophe den Niedergang seiner Seemacht (doch ist 866 davon nicht Notiz genommen). Dagegen blieb der Landweg von Rom über Tuscien nach der Lombardei, und umgekehrt, der über Luna führte, nach wie vor in Frequenz. Als im J. 866 gegen die Sarazenen gerüstet wurde, hatten die Tuscier „cum populo qui de ultra veniunt" auszumarschiren und die Richtung über Rom zu nehmen ${ }^{4}$ ). Nachdem Lothar II. im J. 869 auf der Rückkthr von Rom in Luca erkraukt war, kehrte er wieder genesen über Placentia in die Heimat zurück. Dann kamen die Partikularinteressen empor, so dass Papst Johann VIII. als er im J. 877 nach

1) Prudentii ann. ad a. 860 : Dani, qui in Rhodano fierant, Italiam petunt et Pisas civitatem aliasque capiunt, depraedantur atque devastant.

2) Dudo, de moribus et actis primorum Normanniae ducum I, 3. Dümmler bemerkt in den Forschungen z. deutschen Gesch. VI, 367 : , Hier könnte immerhin eine geschichtliche Thatrache zu Grunde liegen “. Man vgl, anch $\mathrm{Ph}$. Laner in den Mélanges d'ar'chéologie et d' histoire $X, X$ (1899) p. 308, über eine poetische Bearbeitung der Einnabme Roms durch die Saracenen im J. 846 und die Anfänge der Leostadt. Hiezu jedoch N. Archiv XXV, 883.

3) Ueber die Verarbeitung des Stoffes durch einen anglonormannischen Trouvère des 12. Jahrhundı $r$ s, Benoît de St. Maur, und über den Nachklang dieser Sagen in der Literatur überhaupt vgl. Näheres in (Reumonts) , Uebersetzung und Erläuterung von des Claudius Namatianus Heimkehr von Itasius Lemniacus * (Berlin 1872) S. 191. Hịeher gehört wohl auch die Geschichte vom , Meerwunder * im Dresdener Heldenbuch von 1472 (von d. Hagen und A. Primisser, Der Holden Buch Bd II): Agilulf, König der Lasıobarden und seine Gemahlin Deudalinda wohnen in der Nähe des Meeres. Ihre Residenz heisst Luneria. Hier wird die Köngin von einem, Meerwunder überrascht. Vgl. Zeitschrift f. bildende Kunst 1900 (Juni) S. 200.

4) Vgl. Mühlbacher, Reg.1 n. 1198. 
Frankreich reiste, um die Erfüllung der „Verheissungen“" zu erlangen ${ }^{1}$ ), den Seeweg (über Genua) einschlagen musste; denn der Markgraf Adalbert von Tuscien stand ihm feindselig gegenüber. Dagegen war Johann VIII. einige Jahre zuvor (872 oder 873) mit Erfolg für einen Candidaten bei dem Grafen Suppo eingetreten, als nämlich das Bisthum von Luna erledigt war $^{2}$ ). Dieser Candidat hies Waliarius; er wird identisch sein mit den Bischof Gualcherius, dem Karl d. D. ein Privileg verlieh und dessen Streitigkeiten mit dem Abt von Bobbio der Kaiser in seiner Gegenwart entscheiden liess ${ }^{3}$ ).

Eine besondere Rolle spielte Luna gelegentlich des Römerznges Arnulfs (895). Der König schlug mit einem Theil seines Heeres (während der andere über Bologna nach Florenz vorrückte) den Weg über den Mons Bardonis ein. Es war im Dezember und noch dazu die Witterung höchst ungünstig; Regengüıse und Ueberschwemmungen hemmten den Vormarsch. Da unter den Pferden eine Seuche ausbrach, musste man das Gepäck auf gesattelten Ochsen fortschaffen. Auch trat Mangel an Lebensmitteln ein. Endlich traf man in Luna ein, wo man sich einige Erholung gönnen konnte und Arnulf das Weihnachtsfest feierte ${ }^{4}$, seitwärts von Luca, in dem der unfreundlich gesinnte Markgraf Adalbert von Tuscien sass.

Dieselbe Strasse über den Mons Bardonis zogen 3 Jahre später (898) die Tuscier gegen den Kaiser Lambert5); ebenso Berengar, als er im J. 915 nach Rom gieng, um die Kaiserkrone zu erlangen6). Es blieb die gewöhnliche von Pavia (über Luca) vach Rom führende Verbindungslinie, so lange die alten Muchtverhältnisse bestehen blieben, d. b. das Schwergewicht in Tuscien sich nicht von Luca nach Florenz verschob (was in Folge des Investiturstreites geschah).

1) Vgl. über den Bericht des Libellus de imperat. potestate nunmehr Duchesne, les premiers temps de l'état pontifical p. 136 (mit Beziehung auf Lapôtre, Le pape Jean VIII).

2) Vgl. N. Archiv V 298 f. Supponi comiti: obiise Lunensis ecclesie praesulem audientes, ad ipsius successionem satis nobis idoneus et aptus praesentium gerulus litterarum Waliarius nomine visus est. - Utber Stippo vgl. Desimoni, Sulle marche p. 196 f. Er hatte 871-876 die Mark Spoleto inne; er war überdies Graf ron Turin und von Asti.

s) Vgl. Ughelli I2 p. 837. Dipl. Otto II. n. 253 vom J. 981.

4) Annal. Fuldens, ad a. 895: ipse cum Francis per superiores partes Alpium - usque civitatem Lunam I rogreditur. Ibi natale domini celebrat. Vgl. Müblbacher, Gesch. der Karolinger S. 635.

5) Liutprand antap. I, 39-41.

6) Vgl. Duchesne, les premiers temps p. 166. Ueber Berengars Beziehungen zu Tuscien vgl. Dümmler; Gesta Berengarii p. 58. Davidsohn, Geschichte von Florenz I 98. 
In dieser Zeit traten Bisthum und Comitat von Luna deutlicher hervor. Das Gehiet der Stadt, beziehungsweise Comitat und Bisthum war ziemlich ausgedehnt, da im Westen das Thal des Flusses Var dazu gehörte ${ }^{1}$ ); hier grenzte der Comitat von Genua $a^{2}$ ). Im Norden reichte das Lunensische längs der Macra bis an den Kamm des Apennin, der z.vgleich die Grenze von Tuscien bildete. Südwärts waren die Stadtgebiete von Pisa und Luca die Anrainer ${ }^{3}$ ).

Die Bischöfe von Luna finden wir im 9. und 10. Jahrhundert eifrig bemüht, den Besitz ihrer Kirche zu wahren und zu mehren. Die Immunität war ihnen vom Kaiser Karl III. verliehen, von Kaiser Berengar im J. 900 bestätigt worden ${ }^{4}$ ). Ebenso wussten die Bischöfe unter den Ottonen zu ihrem Rechte zu kommen, wie die Urkunden dieser Zeit darthun ${ }^{5}$ ).

In weltlicher Beziehung schalteten die Markgrafen von Tuscien, welche die Grafschaft von Luna (entsprechend dem Umfang des Bisthumssprengels) selbst in der Hand gehalten, eventuell durch einen Sohn des Hauses verwaltet zu haben scheinen; gelegentlich wird ein Vicecomes genannt $\left.{ }^{6}\right)$. Zudem hatte das markgräfliche Geschlecht bedeutenden Grundbesitz inne, der seinen Sprösslingen zu Gute kam, auch als sie von einer Markgrafschaft kaum mehr als den Namen besassen $^{7}$ ), überdies durch zahlreiche Theilungen einzelne Zweige sehr heruntergekommen waren. Die Stellung des alten markgrüflichen

1) Conrad II. (St. 1933, Ughelli I2 p. 840) nennt 1027 , abbatiolam Brumiarlae nomine (d. i. Brugnato) in comitatu Lunensi situm..

2) Die Geschichte dieser Abgrenzungen ist in Dunkel gehüllt. Agathias II,

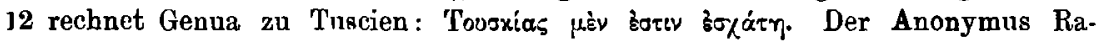
vennas zählt Luna und Genua zur Maritima, Paul. diacon. nimmt Genua, Dertona, Bobbio für die Alpes Cottiae in Anspruch, während er Luna zu Tuscien rechnet. Ueber die Mark Genua vgl. Ficker, Forschungen I, 261 f., 249. Die Otbertiner amtirten auch dort, z. B. in Lavagna (994).

9) In den päpstlichen Bestätigungsbullen (seit Engen III. a. 1149) werden die zum Bisthum Luna gehörigen Pfarrgemeinden (plebes) namentli.h aufgeführt.

4) Ughelli, Itaha sacra I2 835. Dümmler, Gesta Berengarii p. 172 n. 28. Immunitätsurkunde für Bischof Adelbert, mit Berufung auf spraeceptum domni Karoli autoritatesque nostrorum praedecessorum regum c. Das Privileg Karls III. ist, deperditum*.

s) Otto I. im J. 963 (Ughelli I² 836, vg\}. Dümmler-Köpke, Jahrb. Ottos I. S. 345); Otto II. im J. 981

6) Vgl. die Gründungsurkunde des Klosters S. Caprasio zu Aulla im Lunensischen, vom J. 884. Muratori Antich. Estens. I p. 210 . Die Stiftung geht aus vom Grafen, zugleich Markgrafen (comes et marchio) Adalbert. Vgl. Dümmler, Jahrb. III, 16; 369 A. 2.

7) Wobei ich auf Nuratori, Desimoni, Dümmler, Bresslau verweise, ohne auf die controversen Punkte einzugehen. 
Geschlechtes war erschüttert, seitdem Heinrich II. dessen Opposition durch Aechtung und Güterconfiscation gebrochen hatte $\left.(1014)^{1}\right)$. Dafür spielte unter diesem Herrscher wie unter seinem Nachfolger der Bischof Wido von Luna eine nicht uubedeutende Rolle. Als eine der Śtützen der kaiserlichen Partei betheiligte er sich (mit dem Bischof von Volterra) an der Berathung über die italischen Angelegenheiten, die im J. 1019 von Kaiser Heinrich auf einem Reich-tage zu Strassburg abgehalten wurde ${ }^{2}$ ). Er begleitete auch Conrad Il., der über den Mons Bardonis kam, nicht ohne in Tuscien Widerstand zu finden ${ }^{3}$ ), auf seiner Kaiserfahrt nach Rom (1027). Da Conrad weniger schroff vorgieng als sein Vorgänger, hatte dies zugleich zur Folge, dass zwischen den neuen Inhabern der Mark Tuscien und dem alten markgräflichen Hause ein "modus vivendi“ zu Stande $\mathrm{kam}^{4}$ ). Das alte markgräfliche Geschlecht behielt den Comitat vou Luna, dazu Theile der markgräflichen Befugnisse im Gebiete von Genua5). Aber auch die Nachkoumen des Markgrafen Rainer erhielten sich nicht im Besitze der Markyrafschaft Tuscien (wennschon sie in der Gegend von Arezzo reich begütert blieben, den Titel Markgraf und einen Theil der

1) Stumpf 1633. 1634. Vgl. Pabst Jahrb. Heinrichs II. Bd. 2, 435. Bresslau, Jahrb. Konrads II., Bd. 1, 416. H. Bloch, N. Archiv d. Ges. XXII S. 26 ff. Auf die im Einzelnen dunkeln Punkte (wie den Zusammenhang der, Otbertiner* wit den älteren Markgrafen Tusciens) gehe ich nicht ein. An dem Widerstand gegen Heinrich II. betheiligten sich ausser vier Otbrrtiner Markgrafen (drei Söhne Otberts II., einem Sohn Otberts III.) auch der Graf Albert von Parma (St. 1655) und seine Söhne. Die Anschläge der weltlichen Magnaten wurden durch die kirchlichen zu nichte gemacht. Unter diesen befand sich neben den Bischöfen Leo von Vercelli und Heinrich von Parma auch B. Wido von Luna. - Möglich, dass die Otbertiner übrigens nicht alle gegen Heinrich Il. standen. Vgl. Bloch S. 32.

a) Mun. G:rman. Leg. II, 38. Stumpf 1734. Vgl. Bresslau, Jahrb. Heintiche II., Bd. 3, S. 139. H. Bloch, a. a. O. S. 101.

$\left.{ }^{3}\right)$ Vgl. Wipo c. 15: ad Romam tendere coepit. Veniens autem ad Lucam civitatem, invenit eam sıbi adversum cum Reginhero marchione. . . . . post paucos dies civitatem et marchionem in deditionem acceperat.

4) Jabrb. Konrads Bd. 1 S. 136 f. Ueber den (aus der Gegend von Arezzo stammenden) Markgrafen Rainer ebenda S. 444 ff. Ficker, Forschungen I, 263 Anm. 1. II, 245. Desimoni, Sulle marche p. 214 f. Davidsohn, Geschichte von Florenz I, 129.

5) Albert Azzo II. schenkt a. 1050 Güter an das Kloster S. Venerio bei Portovenere; er bezeichnet sich dabei als marchio et comes istius Lunensis comitato, filius b. m. itemque Alberti similiterque Aczo et marchio et comes (wozu doch ebenfalls Luuensis comitatus ergänzt werden muss. Es ist Albert Azzo I., der 1014 in die Verschwörung gegen K. Heinrich II. verwickelt war). Muratori Ant. Estens. I, 83. Vgl. Bresslau, Jahrb. Konrads II., Bd. 1 S. 421.426 f. 
markgräflichen Rechte, z. B. die Notarernennung behielten ${ }^{1}$ ), auch anderswo im Reichsdieuste noch ansehnliche Stellungen bekleịdeten), vielmehr wurde bald nach 1027 Bonifaz von Cdnossa Markgraf in Tuscien ${ }^{2}$ ). Dessen Haus stammte zwar aus Luca, hatte aber dẹn Kern seiner Besitzungen in den Comitaten nordwärts des Apennin, wo dessen Burgen die Uebergänge von Reggio, Modena, Bologna in der Richtung auf Florenz beherrschten. Das wurde für die Amtswaltung des mächtigen Geschlechtes, die fast 90 Jahre (bis 1115) währte, von ausschlaggebeuder Bedeutung. Während seit fünfhundert Jahren die erste Rolle in Tuscien Luca gespieit hatte, $d a$ es die Residenz der Herzoge und Markgrafen war, kam jetzt Florenz in jeder Beziehung zu bevorzugter Geltung ${ }^{3}$ ), auch hinsıchtlich der Verkehrsverhältnisse. Die Markgrafen residirten, wenn sie nach Tuscien kamen, mehr dort als in Luca, wogegen dese Stadt und ebenso Pisa in Opposition traten $^{4}$ ). Das blieb so als die Hinterbliebenen des Markgrafen Bonifaz (gestorben 1050) und namentlich dessen Tochter Mathilde die gegen das Kaiserihum sich erhebende Macht der römischen Kirche unterstützten. Als Heinrich IV. darauf reagirte, hatte er alle durch die neue markgräfliche Gewalt bedrückten Faktoren für sich: die Abkömmlinge des alten Markgrafenhauses der Otbertiner $^{5}$ ), die Städte Luca und Pisa, den Bischof von Luna.

1) Vgl. Ficker, Forsch. II S. 74. 79. I S. 263 A. 1.

2) Vgl. Bresslau a. a. O. 451. Davidsohn, Gesch. von Florenz I, 157. Ughelli I ${ }^{2}$ p. 837 rechnet den Bischof Gottfried von Luna (Zeitgenossen Otto II. und IIl.) zum Hause Canossa. Derselbe sei später nach Brixia versetzt worden. Diese Daten stimmen nicht mit Bresslau S. 433, 435. Uebrigens verschwägerte sich das Haus Canossa anfangs des 11. Jahrhunderts nit den Otbertinern. Ebenda S. 434.

3) Vgl. Davidsohn, Gesch. von Florenz I. 119. 199. 189. Forschungen I, 43. 45. Im J. 1050 weilte P. Leo IX. in Florenz. Im J. 1058 fand in Florenz ein Concil statt. Papst Stephan IX. starb 1058 in Florenz, dessen Bischof Gerhard als Nicolaus II. sein Nachfolger wurde. Nach inm worde 1061 Bischof Anselm von Luca als Alexander II. Papst.

4) Vgl. Ficker, Forschungen I 256, Ili 409. David^ohn, Forschungen I 42 f. Im Privileg für Luca von 1081 sagt Heinrich IV.: consuetudines etiam perversas a tempore Bonifatii marchionis (d. i. zu Anfang des 11. Jahrhunderts, nach Davidsohn) duriter eisdem impositas omnino interdicimus et ne ulterius fiant precipimus. Für Pisa (ebenfalls 108l) : die Leistungen der Stadt werden auf das Mass zurïckgeführt, quomodo fuit consuetudo tempore Ugonis marchionis. (Vgl. über diesen, gest. 100I, Davidsohn, Gesch. von Florenz I 121). Durch eidliche Aussage der ältesten Leute soll das festgestellt werden. - Ueber die Belagerung von Florenz 1082 durch Heinrıch IV. vgl. Davidsobn, Forsch. I $63 \mathrm{f}$. Ebenda über Heinrichs Aufenthalt in Luca (1081) und Pisa (1082).

5) Bestätigung der Besitzungen. für die Abkömmlinge des Markgrafen 
Der Bischof füblte umsomehr das Bedürfnis nach einer starken kaiserlichen Gewalt, weil er sonst den Uebergriffen seiner Nachbarn preisgegeben war. So sehen wir Heinrich III., der überhaupt in Tuscien kräftig eingriff, 1055 persönlich im Hofgerichte zu Roncalia eiuen Streit des Bischofs von Luna gegen Gandulf von Luca entscheiden ${ }^{1}$ ).

Viel Verdruss machte den Bischöfen von Luna die Unbotmässigkeit der Klöster ihrer Diöcese, so namentlich von S. Peter zu Brugnato im Thal des $V_{a r}{ }^{2}$ ). Während von Otto III. im J. 996 diesem Kloster die Unabhängigkeit gegenüber den Ansprüchen des Bischofs von Luna zugesichert worden war $^{3}$ ), hat Conrad Il. dem Bischof Wido dessen Besitz bestätiget ${ }^{4}$ ). Aber ein Jahrhundert nachher (1133) kamen andere Gesichtspunkte zur Geltung. Damals, da Papst Innocenz II: für Genua und Pisa die kirchlichen Verhältnisse einer völligen Neuordnung unterzog, geschah dies, was Genua anlangt, zum Nachtheil der Kirche von Luna. Es wurde nemlich Brugnato zu einem Bischofsitz creirt und dieser der neuen Erzdiöcese von Genua unterstellt ${ }^{5}$ ). Ein anderes Kloster, das sich störrig erwies, war die Familienstiftung der alten Markgrafen S. Caprasio zu Aulla. Weil (um 1130) wegen Krankheit des damaligen Bischofs Philippus von Luna auf dessen

Albertus Azzo II. durch Heinrich IV. im J. 1077. Stumpf 2986. Vgl. Muratorì Ant. Estens. p. 40 f. Bresslau, Jahrb. Conrads II., Bd. 1, 420 f. Der Estensische Zweig des markgräflichen Geseblechtes besass, in comitatu Lunense: Pontremulum, Filateram, Casteulo, Verugula, Mazucasco, Venegla, Comanum, Panigalem cum omni re Guidonis filii Dodonis, abbatia s. Caprasii, Martula und andere Castelle. Die Malaspina erscheinen noch später (z. B. 1202) hier mit den Este enge verknüpft (Lünig II, 253).

1) Muratori Antiquit. III, 645. Stompf 2471. Hiezu Steindorf, Heinrich IIf. Bd. 2 S. 300 und 390 . Ueber Heinrichs III. Eingreifen in Tuscien vgl. Ficker, III S. 410: Begünstigung der Städte gegenüber den Markgrafen.

2) Dessen Immunität hatte Karl Ill. im J. 882 Febr. bestätigt. Mühlbacher, Reg. n. 1591. Hiezu P. Fabre, Étude sur le libre censuum de l'église Romaine p. 51.

3) Vgl. das Diplom K. Otto's III. vom J. 996, n. 201.

4) Stumpf 1933. Vgl. Ficker, Vom Reichsfürstenstand I S. 361.

5) Duchesne, Liber pontifical. II p. 281. Jaffé 7613. Vgl. hiezu P. Fabre in den Mélanges d'archéol. IV (1884) p. 387, wonach die Bischöfe von Bobbio und Brugnato erst 1167 , metropolitico iure von P. Alexander III. Genua unterworfen worden wären. Die Beziehungen des Bischofs von Brugnato zu dem von Luna waren im 13. Jahrhunderte thejls freundliche, wie denn 1202 der B. Sigebald von Brugnato in Kloster Avula (Aulla) das mit den Malaspina getroffene Abkommen-des Bischofs von Luna als Zeuge unterfertigt (Lünig II, 253); theils wurde Brugnato von den Päpsten als Aufsichtsorgan gegenüber der Diöcese Luna (die in den Kämpfen des Kaisers Friedrich II. doch zu diesem halten musste) benützt. 
Ersuchen der Bischof Bernhard von Parma die kirchlichen Funktionen inn Kloster auszurichten übernonmen hatte, fochten die Mönche später mit gewohnter Obstinanz alle Rechte des Diöcesanbischofs an, bis Papst Alexander III. die Sache klarstellen liess; auf Grund des Ergebnisses wurden der ,ecclesia Lunensis“ und ihrem Bischof Peter die alten Rechte bestätigt1).

Streitigkeiten gab es in den Gebirgsdistrikten auch mit dem Kloster Bobbio, das nach allen Seiten um sich griff; so handelte es sich um den Zehnten in einigen Dörfern oder kleineren Ansiedlungen (villae), wobei aber vom Kaiser Otto II. in J. 981 dem Bischof Rechit gegeben wurde ${ }^{2}$.

Um dieselbe Zeit (im J. 998) liess sich der Bischof von Luna durch den Markgrafen Otbert II. vier Pfarrdörfer (plebes) cediren ${ }^{3}$ ).

Mun ersieht aus allem, dass die Otbertiner hier eine mächtige Stellung einnahmen und dass die Bischöfe von ihnen mehrfach abhängig waren. Hingegen scheinen die Markgrafen von Tuscien aus dem Huuse Canossa für Luna nie von ausschlaggebender Bedeutung gewesen zu sein ${ }^{4}$ ); es bahnte sich so die nachherige Sonderstellung des Lunensischen an, oder vielmehr: sie war schon vorhanden.

Unterdess herrschten zur See bis in den Anfang des 11. Jahrhunderts die "Saracenen" von Africa, Sicilien und Hispanien her, so dass die italischen Küsten und Inseln völlig dominirt waren. Eine Flotte der italischen Machthaber oder auch der Kaiser des deutschrömischen Reiches gab es nicht; wohl aber hatte im 10. Jahrbundert die byzantinische Seemacht sich wieder derart gekräftigt, dass sie in ägeischen Meer mit den Feinden aufräumen und auch im Westen interveniren konnte. In der That sehen wir den in Pavia residirenden König Hugo, ebenso Alberich, den princeps et senator Romanorum ${ }^{5}$ ),

1) Ughelli I2 p. 847. Jafté 8719 (im J. 1179 April 25).

2) Stumpf 797. Diplom. Otton. II n. 253. Mein Aufsatz über „Bobbio u. s. w. " S. 532. Die Streitigkeiten reichten bis in die Karolingerzeit zurück.

s) Ughelli [2 p. 838 f. Muratori Antich. Estens. p. 131. Der Markgraf amtirt dabei in Carrara, in brolio

4) Vgl. die Regesten bei Overmann, Die Besitzungen der Grossgräfin Mathilde (1593). Ueber die Stellung der Markgrafen von Tuscien zu den Bischöfen ihres Gebietes im Allgemeinen Ficker Forrch. I S. 253. Dieselben waren in Bezug auf die Temporalien von den Markgrafen abhängig. Sie nabmen, z. B. der von Luca, im 12. Jahrhundert, von den Markgrafen zu Lehen. Vgl. auch Ficker, Vom Reichsfürstenstand 1 S. 317 mit Beziehung auf Cosmas Pragens. M. Germ. 11, 87. Dieser sagt von der Grossgräfin Mathilde, sie habe gehabt potestatem eligendi et intronizandi sive eliminandi 120 super episcopos.

s) Vgl. Duchesne, les premiers temps p. 174. 
mit Byzanz verbündet und verschwägert, eben um der Unterstützung der Flotte willen. Als dann die Ottonen zur Herrschaft gelangten, traten sie durchwegs in dieselben Fusstupfen, wobei die Gattin Ottos I., Adelheid, und die Ottos II., Theophano, als Mittelglieder fungirten.

Von Corsica ist in dieser Zeit mit Beziehung auf Luna nur die Rede, wenn die obligate Bestätigung der Privilegien der römischen Kirche anlässlich einer Kaiserkrönung, so 962, so 1020, ertheilt wurde; es galt dies als blosse Formalität1). Die Iusel war von Zeit zu Zeit den Anfällen der Saracenen preisgegeben; wir hören, wie Papst Stephan VI. (885-891) einem Bischof Sigebert auf Corsica Verzeihung dafür ertheilte, dass er, von den Saracenen gefangen, einen Menschen getödtet habe ${ }^{2}$ ). Im J. 935, als die Saracenen von Africa Genua überfieleu und zerstörten, plünderteu sie auf der Rü:kkehr auch Corsica. In den Jahren 963-@65 flüchtete Adalbert, der Sohn König Berengars, wiederholt nach Corsica, wo er sich vor Otto I. so sicher fühlte, dass er sogar Gefangene dorthinschleppte ${ }^{3}$ ). - Aus dem Umstande dass im J. $996 \mathrm{~K}$. Otto III. auf Bitten des Markgrafen Hugo von Tuscien dem Kloster S. Salvator in Sesto bei Luca unter anderen auch stine Corsicanischen Besitzungen bestätigte ${ }^{4}$ ), ersehen wir, wie der Zusammenhang zwischen der Insel und Tuscien ${ }^{5}$ ) unter derselben Herrschaft wieder hergestellt ist.

Sardinien hielt sich in dieser Zeit unabhängig unter seinen ,iudices", wenngleich auch hier öftere Plünderzüge, z. B. 935, von Seite der Saracenen erwähnt werden ${ }^{6}$ ).

Solche Anfälle betrafen auch die tuscische Küste. Im J. 1004 wurde Pisa genommen und geplündert; und kaum dass die Stadt sich etwas erholt hatte, erlitt sie im J. 1011 dasselbe Schicksal durch aus Hispanien kommende Corsaren ${ }^{7}$ ).

Es folgten andere Züge von Spanien her, da die Balearischen Inseln den Angriffen auf Sardinien und Corsica, diese nach dem italischen Festlande als Zwischenstation dienten. Im J. 1016 landeten Saracenen an der tuscischen Küste, fielen über die Stadt Luna her,

1) Nemlich bis auf Gregor VLI, der die Sache ernst zu nehmen anfieng. Vgl. Duchesne, les premiers temps p. 183. Dove, de Sardinia p. 55.

2) Jaffé 2654 .

s) Vgl. Köpke-Dümmler, Jahrb. Otto's I. S. 344, 354, 368 .

4) Stumpf n. 1087.

5) Vgl Dove, de Sardinia insula p. 52.

5) Dove 1. c. 53 f.

7) Vgl. Bresslau, Jahrb. Heinrich's II. Bd. 3 S. 130. 
zwangen den Bischof (Wido) zur Flucht und schickten sich an, hier festen Fuss zu fassen 1 ), wie seiner Zeit in Fraxinetum oder am Garigliano. Aber wie hundert Jahre vorher (916) die Saracenenburg am Garigliano durch die gemeinsame Anstrengung der angrenzenden Machthaber einschliesslich des Papstes erobert worden war, so beeilten sich jetzt die nicht weniger bedrohten Seestädte Pisa und Genua den Feind hinauszuwerfen. . Der thatkräftige Papst Benedict VIII. rüstete selbst eine Schiffsmacht aus und stellte sich gleichsam als Vertreter des abwesenden Kaisers an die Spitze der Uuternelımunga ${ }^{2}$ ), die vollständigen Erfolg hatte. Die Saracenen wurden geschlagen, ihnen viel Gold abgenommen, auch ihre Königin gefangen.

In den folgenden zwei Jahren giengen die Pisaner und Genuesen angriffsweise vor, fassten Fuss auf Sardınien (das nachber der Zankapfel zwischen ihnen werden sollte) und stellten die Sicherheit inuerhalb ihres Meeres her.

Ein grosser Zeitpunkt in der Geschichte Italiens, das seit Jahrhunderten dem Ausland gegenüber zur Passivität verurtheilt gewesen war. Jetzt fieng man an. wenigstens zur See wieder activ zo werden und die Geschicke des mittelländischen Meeres von den italischen Küsten aus zu bestimmen. Hier an der Westseite fiel diese Rolle den Städteu Pisa und Genua zu, denen der Sieg vom J. 1016 vor allen zu danken war. Sofort unternahmen die Pisaner gegen Sicilien, gegen Africa, gegen die Balearischen Inseln Angriffs- und Plünderzüge ${ }^{3}$ ). Indem sie an den Kreuzzïgen nach dem Orient theilnahmen, umfassten ihre Beziehungen bald des ganze Mittelmeer; sie erscheinen zur See als die Repräsentanten ganz Tusciens ${ }^{4}$ ).

Hingegen konnte sich die Stadt Luna von dem Schlage, der sie betroffen, nicht wieder erholen ${ }^{5}$ ); sie war nicht einmal im Stande, ihr

1) Vgl. Thietmar VII, 31 : In Langobardia Saraceni navigio venientes Lunam civitatem fugato pastore invadunt, et cum potentia ac securitate fines illins regionis inhabitant. - Da der Bischof von Luna 1019 auf dem Reichstage in Strassburg erschien, konnte Thietnar wohl gut Kunde erhalten. Die arabischen Berichte bei Amari, Biblioteca Arabo-Sicula I p. 437 f. Vgl. im Uebrigen Bresslau, Jahrb. Heinrich's Il., Bd. 3 S. 128 ff. Dove, Münchener Sitzungsber. 1894 S. 217 Anm.

2) Vgl. Ducbesne, Les premiers temps p. 198.

s) Ueber die Pisaner auf Corsica in dieser Zeit vgl. Dove, de Sardinia p. $87 \mathrm{f}$.

4) Vgl. Davidsohn, Forschungen II S. 7.

5) Vgl. Promis, dell'antica città di Luni p. 75. Es ist vielleicht bemerkenswert, dass um die Zeit der Katastrophe von 1016 Dudo seine normannische Geschichte (darin der Ueberfall Luna's um das J. 860 gesehildert ist) schr eb (nach 1015 wo er Dekan. wurde, vor 1026 wo er starb). 
Hafengebiet zu behaupten, geschweige denn dass sie zur See hätte eine Rolle spielen könuen. Hingegen hören wir, dass im J. 1113, als die Pisaner zu einem grossen Seezuge gegen die Balearen rüsteten, das Holz zum Schiffbau aus Corsica, dem Quelldistrikt des Arno (dem Mugello) und den Wäldern des Lunensischen Gebietes entnommen wurde ${ }^{1}$ ). Diese müssen damals noch sehr bedeutend gewessen $\operatorname{sein}^{2}$ ), daher sich die Wasserfülle der Flüsse und ihre Schiffbarkeit (sehr verschieden von den heutigen Zuständen) erklärt.

Wenn aber auch nicht die Stadt Luna so hatten sich an jenen Unternehmungen auf Corsica doch die Magnaten des Lunensischen Gebietes betheiligt, namentlich die Markgrafen aus dem Hause der Otbertiner, die dann auch einigen Landgewinn davontrugen ${ }^{3}$ ). Schon 1033 haben dieselben nachweislich Besit/ungen auf Corsica. Markgraf Albert, der 1034 starb, war Herr der Abtei von Plaidello daselbst. In seiner Grabschrift4) wird er als ein Vorkämpfer gegen die Heideu gerïhmt. Er habe Antheil genummen an der Befreiung Corsica's. Der gleichnamige Sohn Alberts, der den Beinamen "Rufus" führte, schenkte 1050 im Verein mit seiner Gemalin, der Gräfin Jolitta (Tochter des Grafen Ubertus von Parma), dem Kloster S. Venerio (im Golf von Spezia) einen auf Corsica gelegenen Hof 5). Einer der Söhne des "Rufus“, Markgraf Hugo vergabt 1103 an S. Venerio die Kirche

1) Laurentii Veronenais de bello Balearico L. (Migne Patrol. Lat. 163) p. 516: - Quidquid tunc habuit nemorosi Corsica ligni, Aut picis, innumeros ratiun defertur ad usus, Lunensesque suo privantur robore silvae. Arboribus caesis remanet Curvaria rara, Antennas, quae vela terant, quod gestet easdem, Arborum robur celsae tribuere Mucellae. Caeditur omne nemus, caesum descendit ad undas".

Vgl. Davidsohn, Gesch. von Florenz I 373. Forschungen I, \&2 f. Der Verf. des Gedichtes, Laurentius ,Veronensis " lebte als Geistlicher in Pisa, wo damals überhaupt eine rege literarische Thätigkeit entfaltet wurde. (Auch Guido Pisanus schreibt damals). Man fühlte, dass ein neues Zeitalter sunischer Kriege ${ }^{\star}$ herangebrochen sei und lebte sich in die klassischen Reminiscenzen ein.

2) Vgl. über die Waldungen im Florentiner Gebiet von demselben Gesichtspunkt aus Davidsohn, Forsch. I 36.

9) Vgl. C. Desimoni, Sulle marche d'Italia p. 249 f.

4) Muratori Ant. Est. p. 102 (nach Desimonis Auslegung).

s) Muratori l. c. p. 230: curtem unam iuris nostri, quam abere visi sumus in insula Corsice loco ubi dicitur Frasso. Andere Schenkungen an dasselbe Kloster aus dem J. 1051, 1052, 1056, 1060, 1094 ebenda p. 231 ff. Es heisst , monasterium beatissimi Venerii, quod est constructum et edificatum in insula que vocatur; Tyrus (Trro) maior ‘. Im J. $10 ; 6$ erfolgt durch den Markgrafen Guido die Schenkung, trium insularum in Porto Veneric. 
S. Gavino auf Corsica 1). Wir werden später sehen wie sich diese Beziehungen der Markgrafen zu den Inseln weiter entwickelt haben ${ }^{2}$ ).

Indessen begaunen die Rivalitäten von Pisa und Genua, die auf Kosten des Lunensischen Gebietes ihre Machtsphäre an den Küsten zu erweitern bestrebt waren. Im J. 1113, eben als die Pisaner auf den Balearischen Inseln kämptten, bemächtigten sich die Genuesen des Portus Veneris, wo sie ein Castell erbauten. Vergebens suchten die Pisaner sie von hier wieder zu verdrängen, wobei der Bischof von Luna mit ihnen auf das engste verbündet erscheint ${ }^{3}$ ). Papst Alexander III., der für Genui Purtei nahm, machte im J. 1173 den Versuch, diese Allianz zu trennen ${ }^{4}$ ); doch blieb der Gegensatz bestehen ${ }^{5}$ ) und die Bischöfe fanden alsbald am Reich einen Rückhalt. - Neben dem Bischof wären die "Markgrafen" die uatürlichen Vertreter der Interessen des Lunensischen Gebietes gewesen, doch paralysirte ihre durch vielfuche Gebietstheilungen hervorgerufene Zwietracht ihr Eingreifen. Einige von ihnen waren geradezu den Genuesen verpflichtet $\left.{ }^{6}\right)$.

Unter diesen Umständen fassten die Pisaner Fuss an der Lunensischen Küste. Auf der anderen Seite trat Luca in den Wettkampf ein, das sich von den Pisanern nicht das Meer rerschliessen lassen

1) Muratori 1. c. p. 243 . C. Desimoni l. c. p. 258.

2) Papst Gregor VII., der auf Grund der Constantin'schen Schenkung und der Privilegien Corsica der römischen Kirche vindicirte, schreibt 1077 Sept. 16 (J. 3791) an die Corsen: , habemus per misericordiam dei in Tuscia multas comitum et nobilium virorum copias ad vestrum adiutorium paratase. Vgl. hiezu Dove, de Sardinia p. 88, der an jene Sprösslinge des Otbertinergeschlechtes denkt.

s) Vgl. Davidsohn, Gesch. von Florenz I 536 f. Forschungen I 112. Die Annalen von Pisa erwähnen zum J. 1162 (Mon. Germ. Script. XIX p. 247), dass P. Alexander III. auf der Reise nath Frankreich im Genuesischen Gebiet, electum Pipinum Lunensium consecravit.

4) Jaffé2 12174 a. Der Papst Alexander III. aus Anagnia, 1173 Nov. 26 an den Bischof von Luna: er wilft ihm vor gemeinsam mit Pisa einen Anschlag auf Portovenere gegen Genua geplant zu haben. - Bezüglich der Chronologie dieses Briefes vgl. Davidsohn, Forsch. I $112 \mathrm{f}$.

s) Vgl. die Ann. Januens. (p. 154) ad a. 1223. Einige Adelige nehmen Lucenser, die nach Genua gehen, gefangen. Sie geben nicht nach, vielmehr una cum episcopo Lunense castrum Trebiani invaserunt. Es wird von den Genuesen vertheidigt, dissipando et concremando terras ipsius episcopi. Erst 1227 wird der Friede zwischen Genua und dem Bischof von Luna wiederhergestellt. Ib. p. 156 .

$\left.{ }^{8}\right)$ Ann. Januens. p. 94 (ad a. 1172) : ein Malaspina ist vasallus archiepiscopi (Januensis). Vgl, ibid. p. 116, 146. Die Markgrafen von Massa erscheinen im J. 1172 als Bündner der Genuesen gegen die Markgrafen Maldepina. Vgi. Davidsohn, Forsch. I S. 110. Desimoni p. 251, 260. 
wollte, in welcher Beziehung ihm von Luna keine Gefahr gedroht hatte.

Endlich kam auch die Apenninenstrasse in Betracht, die Luca sich weder versperrt noch abgelenkt zu sehen wünschte. Sie sollte vielmehr in der hergebruchten Weise über Luca führen.

In dem Privilegium, das Heinrich IV. der während des Investiturstreites kaisertreu erfundenen Stadt Luca am 23. Juni 1081 verlieh, ist auf diese Verkehrs- und Marktverhältnisse besonderes Gewicht gelegt: es wird bestimmt, dass der Handel mit den Lacchesen weder am Meer (wo die Position von Motrone ihnen von den Pisauern bestritten wurde) verhindert' ${ }^{1}$ ), noch dass der Verkehr zwischen Luna und Luca unterbunden werden dürfe ${ }^{2}$ ). Für den Besuch der Märkte in Borgo S. Donino und in Compermio (den Hafen Parma's am Po) werden sie privilegirt, während ihre Concurrenten, die Florentiner, dieses Vortheiles entbehren soliten ${ }^{3}$ ). Man sieht, Luca wusste seine Interessen vortrefflich zu wahren; der Verkehr von Pavia über Borgo S. Donino oder Parma nach Luca von da nach Rom ward in die Hände der Lucchesen gegeben. Sie wurden von den zeitüblichen Hemmungen und Belastungen ansdrücklich eutbunden ${ }^{4}$ ).

Das war der grosse Freileitsbrief der Stadt Luca, die durch Unterstützung des Kaisers ihre Stellung als Hauptstadt von Tuscien (mit welchem Titel sie sich gerne schınïckte) ${ }^{5}$ ) wieder zu erlangen strebte.

1) Ficker, Forschungen IV n. 81 (vgl. I S. 256 ; III S. 408; 413. Davidsohn, Forsch. I 61) : ut si qui homines introierint in fluvio Serculo vel in Motrone cum navi sive cum navibus calsa negotiandi cum Lucensibus, nullus hominum eos vel Lucenses vel in suprascriptis fluminibus - molestare - presumat. Eben Motrone und castrum Aghinolfi (bei Viareggio) waren die Punkte um die zwischen Pisa und Luca die beftigsten Kämpfe entbrannten. Vgl. Ann. Pisani ad a. 1144: Pisani propter iniuriam de castro Aghinolfi et de Strata Francor u m et Arni eis illatam, gehen gegen Luca vor. Letzteres versuchte Pisa rom transapenninischen Verkehr auszuschliessen. Motrone in den Händen der Pisaner beherrschte die Strasse von Luna nach Luca. Vgl. Sardo, cron. Pisan. p. 85. Vgl. auch Scheffer-Boichorst, Mitth. d. Instit. VIII, $419 \mathrm{f}$.

2) Lt si qui negotiatores venient per stratam a Luna uque Lucam. nullus homo eos venire interdicat vel alio conducat sive ad sinistram eos retorqueat, sed secure usque Lucam veniant.

3) Lucenses licentiam habeant emendi et vendendi in mercato sancti Domnini et Comparmuli, ea conditione, ut Flo:entini predictam licentiam non habeant.

4) Ut nemo deinceps aliquod fodrum ab illis exigat, et curaturam a Papia usque Romam .....

s) Gloriosa civitas luca multis dignitatibus decorata atque super Tusciae marchiam caput ab exordio constitutac. So heisst sie in der sofort zu erwähnenden Urkunde von 1124. 
Die nach dem Tode der Grossgräfin Mathilde (1115) amtweise vom Kaiser nach Tuscien gesetzten Markgrafen deutscher Herkunft stützten sich auf Luca - gegen Florenz, das dem gegnerischen Lager angehörte ${ }^{1}$ ). Das Uebergewicht Luca's auch in Gebiete von Luma zeigt sich deutlich darin, dass im J. 1124 ein wichtiger Rechtshandel zwischen den Angehörigen des alten Markgrafengeschlechtes èxierseits and dem Bischof von Luna anderseits geradezu in Luca zum Austrag gebracht wurde; wobei die Consules dieser Stadt als die Schiedsrichter fungirten ${ }^{2}$ ). Es handelte sich um den Besitz von Caprione, unweit von Luna, am Meer ${ }^{3}$ ). Wir lernen bei dieser Gelegenheit die weite Verzweignng der Markgrafen (die als Malaspina, Este, Palavicini u. s. w. eine bedeutende Rolle in der Geschichte des Landes spielteir) näher kennen 4 ).

Die Markgrafen waren nach wie vor neben den Bischöfen von Luna die grössten Gruudbesitzer und der wichtigste politische Faktor des Gebietes; der Zweig der im Lunensischen die grösste Bedeutung hatte, waren die Malaspina, ohne dass deswegen die anderen Zweige, die ihren Schwerpunkt in die transapenninischen Gegenden verlegt hatten, aller Fühlung mit dem Stamnilande baar gegangen wären. Aber der sichere Zugang zu dem Apenninenpass „Cisa" hieug von den Malaspina ab, die an der Macra, am Taro, an der Trebbia ihre Burgen batten.

Sie waren in Folge dessen den Städten zu beiden Seiten des Gebirges unbequeme Nachbarn, standen übrigens mit denselben in wechselnder bald freundlicher bald feindlicher Beziehung 5 ). Desgleichen

1) Vgl. Scheffer-Boichorst in den Mitth. d. Instit. VIII $400,410,413,418 \mathrm{f}$. 422. Das Privileg Heinrichs IV. bestätigte den Lucchesen sowohl Heinrich V. wie Lothar; vgl. Stun pf, Acta ined. n. 98. Hiezu Ficker, Forsch. III, $408 \mathrm{f}$. (ebenda I 256 über das Privileg für Pisa vom J. 1081). Der neue Markgraf von Tuscien, Konrad (aus baieriscbem Gerchlecht), bestätigte ebenso 1120 den Einwohnern und Bürgern von Luca alle Privilegien der Kaiser und Markgrafen, namentlich Freiheit vom pisanischen Lferzoll. Auch machte er der Stadt und dem Dome Geschenke. Als treilich der vom Kaiser Lothar geschickte Markgraf Engelbert (ans dem Hause der Ortenburger) sich den Pisanern zuneigte; brachten ihm 1136 die Lucchesen bei Fucecchio eine Niederlage bei. Ann. Pisani ad a. 1137.

2) Muratori Ant. Estens. I p. 154 (mit Verbesserung von Ughelli I² p. 841). Auch bei Lünig, Cod. Ital. diplom. Ir, $247 \mathrm{f}$.

s) Jenseits der Mündung der Marra. Die äusserste Spitze des Vorgebirges Caprione war nach dem Raben benannt (Corvaria).

4) Vgl. Bresslau, Jahrb. Conrads II, Bd. ] S. 420. Desimoni, Sulle marche (seconda ediz.) p. $242 \mathrm{f}$.

5) Zur Zeit des Thronstreites zwischen Lothar von Supplinburg und Conrad (III.) scheinen sie zum Staufer gehalten zu haben. Der Mailänder Chronist 
hatte der Bischof vou Luna oftmals mit ihnen Händel1). In uniruhigen Zeiten verlegten sich die "Marchesen" und ihre Genossen wohl geradezu auf den Strassenraub. So sind im J. 1136 (da überhaupt in Tuscien Anarchie herrschte) die von dem Concil zu Pisa nach der Heimat zurückreisenden französischen Prälaten in der Nähe von Pontremoli überfallen, verwundet und in die Castelle geschleppt worden, worüber ein Leidensgefährte, der Abt Peter von Cluny, an den Papst. Innocenz II. einen Klagebrief gerichtet hat').

Die Markgrafen machten aus Heldenthaten dieser Art kein Hehl, wie denn jener Opizo Mlalaspina, der im J. 1167 den Kaiser Friedrich auf der Rückkunft von Rum (da Pontremoli den Durchgang wehrte)

Landulf meldet c. 54: Hunc namque gradientem per comitatus et marchias Lombardie et Tuscie comites et marchiones - cum gaudio susceperunt et amaverunt. Vgl. Scheffer-Boichorst, Mittb. d. Inst. VIII, 422.

1) Diesen suchten sich die Vasallen des Bischofs zu entziehen. Im J. 1197 berichtet eine Urkunde (Muratori, Ant. Est. p. 256) : Masnerius, Marchesellus et Salvagins filii quondam Bonaccursi de Marciasio juraverunt fidelitatem Gualtero episcopo Lunensi contra omnes bomines, exceptis dominis de Fosdenova, et exceptis marchionibus de Massa, et exceptis marchionibus Cavalcaboves, qui omnes marchiones ... excipiuntur. Ebenso nimmt $1202 \mathrm{der}$ Bischof von Luna in der Einigung mit den Markgrafen Albert, Wilhelı, Conrad Malaspina aus die Pontremulenses (die auch von den Markgrafen ausgenommen wurden), die von Luca u. a. Lünig, Cod. Ital. II, 25̉3. Der Bischof dalf nicht fidelitatem recipere contra marchiones von Irgendeinem, der Vasall der Maikgrafen ist (Streitpunkt).

2) Petri Venerabilıs ep. I, 27 (bei Bonquet $X V$ p. 629 f. vgl. Bernbardi, Lothar ron Supplinburg S. 643 Anm. 1): ,Regressi ab uberibus vocantis ecclesiae . . . luporum morsus incurrimus . . et captivati, vulnerati et rebus omnibus pene exspoliati sumus... Episcoporum atque abbatum plurimi ad proxima castra violenter abducti et quidum eorum post verbera et vulnera barbarica imm initate incarcerati sunt .......... cum Bturicensis et Senonensis .. vix ad Pontem Tremuli pervenerint et ibi cum Ebredunensi, Trecensi ictu hastae de equo deiecto et inde graviter infirmato, - inclusi teneantur. Refertus est burgus ille et constipatus multitudine sinctorum . . . . Nulli tutus ingressus, omnibus negatur egressus .... de meis iniuriis plura dicere supersedeo: qui dum cum domino Vizelaciensi abbate armatis hostibus pro pace sociorum obvius occurrissem, primo impetu mula nostra ictu lanceae confossa in partem cedere coacta est, fratres no:tri fugati, famuli capti, res pene omnes ablatae. Ego ad proximam villam me conferens tamdiu delitui, donec conductu hospitis nostri ad Pontem Tremulum, quo alii praecesserant, vespertinis horis et ipse perveni ${ }^{\sigma}$. - Ein ähnlicher Ueberfall wurde 1158 auf die päpstlichen Gesandten im Tridentinischen durch zwei Sprö̈slinge des Grafengeschlechtes von Eppan ausgeführt, worüber Otto Frixing. (Ragewin) in den Gesta Friderici imp. III, 21 berichtet. Man hoffte: in hoc casu latrocinium honestiori nomine posse palliaric. Der Ruf von der Reise der Legaten hatte sich verbreitet per omnes partes illas, ubi arta montium transituri erant. 
anf Seitenwegen über das Gebirge nach Pavia brachte, dem Kaiser anf seine Frage direkt die Antwort gegeben baben soll: in diesen Gegrenden, die sonst nichts hervorbrächten, lebe man eben vom Ruube ${ }^{1}$ ). In der That, als im J. 1155 Terdona von den Kaiserlichen eingenommen wurde, befreiten sie dortselbst einen vornehmen Griechen, den Opizo Malaspina gifangen genommen hatte und hier eingesperrt hielt, um Geld zu erpressen ${ }^{2}$ ).

Die Markgrafen oder wenigstens ein Theil derselben (denn schliesslich gab es in allen Parteilagern Malaspinas) zeigten sich, sobald unter Friedrich I. das Reichsregiment wieder auf feste Füsse gestellt war, schon des Gegensatzes zu den Städten ${ }^{3}$ ) halber bereit, sich der kaiserlichen Partei anzuschliessen. Im J. 1164 bestätigte Kaiser Friedrich dem Markgrafen Opizo Malaspina und dessen legitimen Erben seine Besitzungen und seine markgräflichen Rechte ${ }^{4}$ ). Er wird als reichsunmittelisarer Magnat anerkannt. Gottfried von Viterbo, der Gegend und Leute genau kannte, schildert diesen Opizo Malaspina wie einen grossen Herren ${ }^{5}$ ).

Indem das Privileg von 1164 im J. 1220 von Friedrich II. bestätigt' $)$ und auch in den späteren Zeiten respektirt wurde, bildete es die staatsrechtliche Grundlage der Malaspina'schen Hausmacht, die mit dem $\mathbf{P}_{\text {asse, }}$ der ans Tuscien nach der Lonbardei fïlırte, auf das innigste verwoben war.

1) Der Gibellinische Annalist von Placentia. Mon. Germ. Script. XVIII, p. 462. Vgl. ,Bobbio" S. 545 A. 1.

2) Otton. Frising. Gesta Friderici 15, 20: eripitur ibi de gravi qua tenebatur captivitate quidam ex Graecorum proceribus, quem Opicius cognomento Malaspina male propter pecuniae exactionem ceperat, asperisque locis inclusum in ipsa arce tenebut.

s) Namentlich Placentia und Parma. Die Annales Placent. melden zu den J. 1145, 1150, 1183, 1191, 1195 Abtretungen und Einbürgerungen von Malaspina's.

4) Muratori, Ant. Estens. 1, 161. Vgl. Ficker, Forschungen I, 262. II, 274. Vom. Reichsfüı stenstand \& 186.

s) Gotıfred. Viterb. gest. Frid. v. $745 \mathrm{ff}$.

Opizo markise, quem tunc Malaspina vocabant, Magnus apud Ligures nostros vebementer amabat:

Dum labor instabat, commoda multa dabat.

Quod maris aut terrae mons Appenninus habebat, Opizo quem memini proprio sub iure tenebat,

Et que turba fera venerat, eius erat.

Vgl. im Uebrigen mein , Bobbio* S. $543 \mathrm{f}$.

6) Böhmer-Ficker n. 1255. - Es ist bemerkenswert, dass als im August 1216 die Mailänder und Placentiner wegen ihres Krieges gegen Pavia excommunicirt wurden, speciell auch, marchioni Malaspine die Sentenz zugestellt wurde. Mon. Germ. epist. s. XIII tom. 1 p. 4. 
Aber auch mit dem anderen Factor, der vermöge seiner Besitzungen und seiner Machtstellung hier in Betracht kam, musste gerechnet werden, mit dem Bischof von Luna. Besass doch dieser längs der Macra und in ihren Seitenthälern nicht weniger Castelle und anderweitige Besitzungen wie die Malaspina ${ }^{1}$ ). Diese lagen vielmehr durch- und nebeneinander. Wer von Luna dem Cisapasse zuzog, kam durch S. Stefano, das dem Bischof gehörte, über Villafranca, Mulazzo, Filatera, wo die Malaspina hausten, nach Pontremoli, das wechselnden Antrieben zu gehorchen pflegte. Die Malaspina waren in der Nachbarschaft von Pontremoli bis auf die Höhe des Ueberganges begütert, desgleichen der Bischof, dessen Diöcese bis hieher reichte, der aber auch jenseits, in Parmesanischen Besitzungen hatte. Montelungo knapp unter der Cisa gehörte den Malaspina. Andererseits standen die zahlreichen Hospize unterwegs in geistlicher Verwaltung ${ }^{2}$ ). Es ist bemerkenswert für diesen Stand der Dinge, dass nach dem Ereignis von 1136, als jener Ueberfall bei Pontremoli geschehen war, der Unwille der geschädigten Prälaten in erster Linie sich gegen den $\mathrm{Bi}$ schof von Luna wendete, der sich nicht bemüht hatte, gesichertes Geleite zu geben. Der Abt Peter von Cluny verlangte sogar, dass das gesammte Bisthum Luna gestraft würde ${ }^{3}$ ).

1) Man vgl. hiefür das Laudum, durch welches 1202 die Streitigkeiten 2wischen dem Bischof von Luna und drei Markgrafen Malaspina beigelegt werden. lünig, Cod. Ital. dipl. II, 253 ff. Hii sunt confines, infra quos de hiis, que dicentur inferius, teneantur videlicet a Ponte de Strata comprehendendo curiam Corvarie et Vallecle usque ad montem qui dicitur Juva, et ab eo monte usque ad summitates Alpium usque ad Cisam et inde comprehendendo totum districtum Ponticli et Mulazi et Zovagali et Calese, et eundo usque ad Padulvarinum, et in eundo usque ad Carpenam, comprehendendo totam curiam et districtum Carpene, Vezani. Foli, Vallerani, Bevelini, Vesigne et Pulverarie, et inde eundo per maris littora usque subter Brancalianum, et inde usque ad Pontem de Strata, qui est in capite Brancaliani. Vgl. über die Besitzungen des Bischofs die Bestätigung Friedrichs I. von 1185 (St. 4428).

2) Nicht ohne dass auch Luca darauf Einfluss zu gewinnen gesucht hätte. Im J. 1151 : prope castellum Meliae iuxta flumen, quod dicitur Magra - Gotefretus - Lunensis civitatis episcopus dedit et supposuit ecclesiam et plebem s. Andreae de Carraria ecclesiae et canonicae et decretis s. Frigidiani (Lucensis) - cum hospitali montis Furculi et cum capellis suis, vl. s. Sixti, s. Brancatii et cum hospitali s. Leonardi de Padule etc. Vgl. auch das Itinerar Mon. Germ. Script. XVII p. 131.

3) Petrus Venerabilis 1. c. Precatur nobiscum et consulit sacer captivitatis conventus, ut non solum in actores nequitiae huius, sed et in toto Lunensi episcopatu apostolicae vindictae mucro resplendeat..... Es müsse ein Exempel statuirt werden, das überall bemerkt werde. - (Dieses kann nicht so streng vollführt worden sein; im J. 1149 bestätigt P. Eugen IIl. dem Bischof Gottfried 
Also schien es angezeigt, auch den Bischof von Luna, wenngleich er nicht so gewaltthätig war wie die Markgrafen Malaspina, überdies am Fusse des Gebirges seinem geistlichen Amt lebte, für das Interesse des Reiches zu verwerten. Es geschah dies indem Kaiser Friedrich I. im J. 1183 dem Bischof Peter die Grafengewalt innerhalb des ganzen Lunensischen Gebiets verlieh, so dass er in der Folge unter den mittelitalischen Bischöfen als Reichsfürst eine bevorzugte Stellung einnahm 1). Das Privileg wurde durch Heinrich VI. bestätigt?) und überhaupt diese Organisation aufrecht erhalten bis zum J. 1239.

Unterdessen war der Krieg zwischen Genua und Pisa von neuem entbrannt, und da Pisa an der Küste den Interessen von Luca entgegenwirkte, stand dieses nunmehr auf Seite der Genuesen. Das Reich aber wendete seine Gunst den Pisanern zu, die ihre Flotte zu den Unternehmungen gegen das Königreich Sicilien zur Verfügung stellten: Dafür wurde ibnen vom Kaiser Heinrich VI. verbürgt, dass der Bischof von Luna als Inhaber der Regalien und der Grafschaft die Verkehrsinteressen der Pisaner innerhalb seines Machtbereiches wahren werde ${ }^{3}$ ).

seine Besitzungen. Ughelli $I^{2}$ p. 845). Abt Peter beklagt sich über das Verhalten des Bischofs: Lunensis episcopus nobis in brevi apparens lunarem eclipsim nimis immature passus est, quem dum per totam dietam nobis lucere credidimus, vix per integram leucam socium habere potuimus. - Im J. 1158 suchten die päpstlichen Gesandten sich bei dem Durchzug durch die Diöcese Trident durch das Geleite des Bischofs zu sichern. Otton. Frising. et Ragewini Gesta Friderici III, 22: per vallem Tridentinam iter agunt, habentes secum gratia maioris securitatis venerabilem episcopum Tridentinum Albertum. - Sed praevaluit auri sacra fames . . . .

1) Ughelli $I^{2} 848$. Vgl. Ficker, Vom Reichsfürstenstande \$ 223. Ital. Forschungen I S. 255. II S. 202. Nur der Bischof von Volaterra hatte eine ähnliche Stellung. Ausnahmoweise nennt Christian von Mainz im J. 1165 auch den Bischof von Arezzo sprinceps". Scheffer-Boichorst, N. Archiv XXIV, 130. Davidsohn, Forsch. I $100 \mathrm{f}$. Bischof Peter von Luna war gelehrt und ein tüchtiger Diplomat, der auch als päpstlicher Legat an den Unterhandlungen in Konstanz sich betheiligte (1183). Vgl. Giesebrecht, Kaiserzeit VI, 25, 31, 111 f. SchefferBoichorst, Kaiser Friedrich I. letzter Streit mit der Curie S. 28, 172.

2) Stumpf 4684 (vom J. 1191). Der Bischof nennt sich seitdem , episcopus et comes Lunensis<. So Bischof Buttafava im J. 1225. Ughelli I ${ }^{2}$ p. 853. In der Finigung des J. 1202 verpflichten sich die Malaspina den Bischof zu unterstützen , pro episcopatu vel comitatu, ipse vel alia persona pro eo

s) Privileg Heinrichs VI. für Pisa 1191 März 1 (im Uebrigen basirt auf das Friedrichs I. von 1162 April 6): , faciemus iurare episcopum Lunensem, qui investituram regalium et comitatus a nobis receperit vel quicumque alius pro nobis tenuerit, ut faciat Pisanos sicuros et res eorum salve sint in omni districtu suo pro se et pro omnibus suorum ‘. In der Bestätigung Otto.IV. 1209 Okt. 25 ist dieser Passus weggelassen. Böhmer-Ficker n. 307. 
Im J. 1210 wurde ausgemacht, dass auch die Markgrafen Malaspina gegen Genua Hilfe leisten sollten ${ }^{1}$ ).

$\mathrm{Zu}$ derselben Zeit wüthete der Kampf um die Beherrschung des Apenninüberganges zwischen den rivalisirenden Communen des Polandes, Placentia und Parma, woran die Malaspina eifrig sich betheiligten ${ }^{2}$ ). Wenn sie kein Geld mehr hatten, verkauften sie wohl eine der den Pass beherrschenden Burgen an die durch die Ausnützung von Handel und Verkehr stetig wohlhabender werdenden Städte. Da die Kämpfe in den Berggegenden mit grosser Wildheit geführt zu werden pflegten, sehen sich gelegentlich die Bischöfe veranlasst $z u$ interveniren, so im J. 1229, wo die Placentiner gegen die Pontremulenser standen, die von Placentia und von Luna ${ }^{3}$ ).

Zehn Jahre später begann Kaiser Friedrich II. eine neue Organisation durchzuführen, indem er die Comitatsverwaltung nicht nur dem Bischof von Luna abnahm, sondern sie ganz sistirte, die dem Bischof gehörigen festen Punkte selbst in die Hand nahm ${ }^{4}$ ) und vor allem den Schlüssel zum Apenninübergang, die Feste Pontremoli, mit einer aus Apuliern bestehenden Besatzung versah. Das Gebiet von Luna wurde im Anschluss an die in Oberitalien getroffenen Verfügungen nunmehr einem Generalvikar untergeben, der ebenso in Pontremoli wie in Portovenere, also im Gebirge und an der Küste (hier gegen die Genuesen) das Interesse des Kaisers zu wahren hatte ${ }^{5}$ ). Dabei ist

1) Böhmer-Ficker Reg. n. 411. Böhmer, Acta n. 1071.

2) Vgl. Annal. Placent. ad a. 1229. Hiezu Böhmer-Ficker-Winkelmann n. 13028. - Ann. Parmens. ad a. 1230: Parmenses iverunt Pontremulum contra Malaspinos; cf. ad a. 1231.

3) Annal. Placent. ad a. 1229: occaxione quia episcopus Placentie et Lunensis episcopus et quidam alii viri potentes pacem et concordiam inter comune Placentie et Pontremulenses facere et componere studebant.

4) Vgl. Winkelmann Acta imp. ined. II n. 1237. Friedrich versprach von Pisa aus 1239 Dez. 23, die Häłser und Thürme in Vezano (am Var, unweit dessen Mündung in die Macra), Ponzanello und Fosdenova (ostwärts von Sarzana und der Macra), welche ihm der Bischof ron Luna zur Bewachung überlassen hat, nach Beendigung des lombardischen Krieges zurückzugeben. Die Annal. Placent. ad a. berichten : episcopum Lune vinculatum ducere fecit post se.

5) Vgl. Ficker, Ital. Forschungen II S. 498, 500, 506. Der zum Generalvikar bestellte Hubert Pelavicini wird (in den Placentiner Annalen) als vicarius in Lunexana et Pontremulensi bezeichnet, er heisst auch capitaneus in Lunesana; 1241 : vicarius in Lunexana et partibus convicinis; 1243 : sacri imperii in Lunigiana, Versilia, Garfagnana et partibus convicinis vicarius generalis. - Muratori Ant. Estens. p. 258 citirt einen Codex manuscr. aus Sarzana: , iste liber vocatur magister et compositus et factus fuit tempore $d$. Uberti Pelavisini generalis vicarii in provincia Lunisiana de mandato et auctoritate ipsius ‘. Vgl. Ottenthal in den Mitth. d. Inst. IV, 609. 
bemerkenswert, dass die "Lunigiana" — dieser Name tritt von da. ab hervor - ein von Tuscien abgetrenntes Vicariat bildet; auch dies. mit Rücksicht sowohl auf die bisherige Entwicklung der Dinge wie vor allem auf die hier durchführende wichtige Verkehrsstrasse, die der Kaiser, wenn er aus dem Süden nach der Lombardei gieng oder wenn er von dort zurückkehrte, meistens benutzte ${ }^{1}$ ).

Eine kurze Zeit hindurch finden wir die "Lunensische Provinz" dem jungen König Heinrich (Enzio) von Torre und Gallura untergeben, da für die Herrschaft auf Sardinien eine solche Stellung von Wert war ${ }^{2}$ ). Aber auch die Pisaner waren danach lüstern, . so dass. der Kaiser, da er nach dem Abfall von Parma (1247) seine Positionen in diesen Gegenden mit neuen Stützen versehen musste ${ }^{3}$ ) (auch die Malaspina und die Lunigiana hatten in ihrer Trene gewankt), den Pisanern 1248 thatsächlich entgegenkam. Sie erhielten die „provincia Lunisiane" in Anbetracht ihrer Treue zu Lehen, nur dass der Kaiser Pontremoli für sich behielt, und auch die Markgrafen Malaspina in ihrer reichsunmittelbaren Stellung belassen wurden ${ }^{4}$ ). Während der folgenden Jahre hat es sich wiederholt um den Besitz von Pontremoli gehandelt, das einmal geradezu als "unica clavis et ianua" des Reiches. bezeichnet wird 5 ). Wir kommen darauf später zurück.

In Uebrigen haben die Organisationen Kaiser Friedrichs II. in der Lunigiana auch für die Folgezeit nachgewirkt; unter den letzten Staufern, unter Karl von Anjou, unter Heinrich VII. erscheint ein

1) So im J. 1226, bei welcher Gelegenheit den Sarzanesen und Pontremolensern ihre Privilegien bestätigt worden waren; 1239, 1245 (im Mai nordwärts, im Dezember zurück), 1247, 1249. Vgl. F. Ludwig, Unters, über die Reise- und Marschgeschwindigkeit im 12. und 13. Jahrbundert. S. 189.

2) Vgl. über Enzio Davidsohn, Forschungen Il S. 41 ff. Er war seit 1239 , Reichslegat Italiens, als solcher in Tuscien mit Pisa Hand in Hand gehend (gegen Genua).

s) Vgl. die Ann. Placentini ad. a. 1247. - Neues Material für diese Kämpfo auch mit Bezug auf die Lunigiana bietet Davidsohn, Forschungen zur Gesch. von Florenz II (1900) aus den Archivalien von S. Gimignano. Vgl. Reg. n. 471 : Soldzahlung für die 1247 im kaiserlichen Dienste, in Lunisiana befindlichen milites: n. 480 einer der pedites dortselbst gefangen (1247); n. 501, 502, 512, 523 (ad a. 1248): Soldzahlung nach Pontremoli an die milites der Commune.

4) Winkelmann, Acta imperii ined. n. 415: quod licet nos olim provinciam. Lunisiane cum iuribus et pertinenciis suis Henrico illustri regi Sardinie, sacri imperii in Ytalia legato - de mera donatione nostra duxerimus conferendam, tamen - provinciam istam cum castris etc. exceptis castro Pontis Tremuli et terra Conradi marchionis Malaspine, que dictioni et homagio imperii specialiter reservamus, eidem comuni Pisarum - in rectum feudum duximus concedendum.

5) Böhmer-Ficker n. 3785 . 
Generalcapitän an der Spitze $\left.{ }^{1}\right)$. Daneben bleiben die Malaspina als "Markgrafen" anerkannt. Der Bischof hat den Titel "comes" beibehalten und erfreut sich des Besitzes von Regalien, wie des Münzrechtes²); er kann daher immerhin auf einen stattlichen Codex verbriefter Rechte und Einkünfte hinweisen, den im J. 1287 Bischof Heinrich dem Notar Egidius de Beligneo zusammenzustellen befahl ${ }^{3}$ ); er ist die Quelle, aus der Ughelli und Muratori geschöpft haben.

Dabei dauerten die Uebergriffe der benachbarten grossen Communen : Luca, Pisa, Genua stetig fort. Die Lucchesen hielten Motrone besetzt; die Genuesen das ganze Lunensische Gebiet jenseits des Flusses Macra4), nicht ohne dass auch die Pisaner einzelne Positionen zu behaupten gesucht hätten, so castrum Illicis (d. i. Lerici), ferner Trebianum (an der Macra, j. Trebiano) ${ }^{5}$ ). Der Haupthafeu, Portus Veneris, war und blieb in den Händen der Geuuesen; diese kämpften mit kurzen Unterbrechungen gegen Pisa auch auf Sardinien und in den überseeischen Ländern, gelegentlich von den Lucchesen durch Subsidien unterstütat ${ }^{6}$ ).

An Streitigkeiten zwischen den Bischöfen und den Malaspina fehlte es in der Folgezeit, so wenig wie früher. Im J. 1306 fungirte der aus Florenz verbannte Dichter Dante als Vermittler zwischen einigen Malaspina und dem Bischof Antonius von Luna?). Zwei Jahre nachher sehen wir in Parma einen Franceschinus Malaspina

1) Er heisst, generalis capitaneus dioecesis et episcopatus Lunensis`, im J. 1312. Bonaini, Acta Henrici VII, p. 269.

2) Bischof Heinrich von Luna (1273-1296) bekam im J. 1285, Mai 15 das Münzrecht durch Rudolf von Habsburg ertheilt. Vgl. Ughelli $I^{2}$ p. 853. Hiezu Redlich, Regesten Rudolfs n. 1898.

3) Vgl. Ottenthal, Mitth. d. Instituts IV, $608 \mathrm{f}$. Bischof Heinrich bezeichnet sich darin als „dei gratia Lunensis episcopus et comes". - Der „Codex Pallavicinus" bildete hinfort einen 'Theil dieses Copialbuches der Kirche von Luna.

4) Im J. 1292 nehmen die Genuesen für sich in Anspruch: quicquid episcopus Lunensis ab aquae Macre citra versus Januam vel districtum et comune Janue habeat. Ann. Januens. p. 350.

5) Im J. 1223 griffen die Lucenser im Bunde mit dem Bischot von Luna castrum Trebiani an. Ann. Januens. ad a.

6) Vgl. Ann. Januens. p. 229. 231 ff. (ad a. 1254 und den zwei folgenden Jahren). Hiezu Caro, Genua und die Mächte am Mittelmeer I 16 ff. Die Pisaner mussten damals ihre Positionen an der Macramündung rüumen. Im Jahre 1257 überbringen Gesandte von Luca der Commune von Genua 2000 Mark Silber sad subsidium expensarum factarum in exercitu transmarino et Sardinee ; was die Genuesen dies einemal annehmen, um die Lucchesen nicht zu beleidigen (p. 240).

7) Dantis Alligherii legatio pro Francischino Malaspina. Herausgegeben von Lord Vernon. Pisa 1847. 
mit einen Gefolge von Leuten aus der Lunigiana eine Rolle spielen ${ }^{1}$ ). Als Heinrich VII., der Luxemburger, in diesen Gegenden sich anf hielt, $(1312,1313)$ und die Gibellinenpartei zu reorganisiren trachtete $\left.{ }^{2}\right)_{+}$ kritisirte er die "Siege" der Lucchesen „in partibus Malaspinis, Lunisiane et Garfagnane", da durch dieselben wichts entschieden würde ${ }^{3}$ ). Ludwig der Bayer stützte sich auf den Condottiere Castruccio Castracani, der im Dienste Iuca's als Vicecomes des Lunensischen emporgekommen war4); er ernannte ihn zum Herzog der Gebiete von Luca, Pistoja, Volterra und Luna $\left.(1327,1328)^{5}\right)$.

Karl IV., der schon als Jüngling unter seinem Vater Johann in diese Gegenden gekommen war ${ }^{6}$ ), griff auf seinem ersten Römerzuge (1355) hier ein, indem er den Pisanern und den Malaspina die aus der Stauferzeit überlieferten Privilegien bestätigte?). Luca, das in Abhängigkeit von Pisa gerathen war, machte sich unter bezahlter Beihilfe des Kaisers (1370) wieder frei und erwehrte sich mit HilfeGenua's auch der Florentiner, die den Arno abwärts sich auszubreiten suchten. Alles in Allem: die Entwicklung war zu einem gewissen Abschlusse gediehen.

In dieser Zeit existirte die Stadt Luna nur noch als ein unbewohnter Trümmerhaufen, so dass Dante der gleich anderen Florentiner Vertriebenen viel in der Gegend weilte, sie als Beispiel anführt von dem Wechsel der Dinge, dem nicht nur die Menschen sondern

1) Ann. Parmens. maior. ad a. 1308: com certis hominibus de Lulixana.

2) Bonaini, Acta Henrici VIL p. 269, 271, 303, 305. (Beziehungen zu den Malaspina). Vgl. auch die Annal. Parmens. maior. ad a. 1312.

s) Acta Henrici VII Bd. 2 p. 100.

4) In den J. 1316 und 1317 war er capitaneus et defensor comitat. Lucani et vicecomes Lunensis. Vgl. Davidsohn, Forsch. II S. 279 n. 2169. S. 280 n. 2179 .

5) Lünig, Cod. Ital. dipl. II 2218: de consilio principum et baronum civitatis Lucae, Pistorii, Volaterrarum et Lunae. Sein Titel ist knrzweg: Herzog ron Luca. Bereits 1324 war Castruccio von Ludwig zu seinem Vicar ernannt worden, nicht nur von Luca sondern auch provinciarum vallis Nebulae, Arianae et Lunae et terris civium Garfagnanae, terris, quae dicuntur Plancorum, Verrucula, Bossorum, et eius curiae, Pontremulo, eius districtu Lunegiana, et omnibus terris, sitis citra et ultra aquam Magrae, in Lunensi dioecesi, Massa et Versilia et Valletina. (Lünig l. c. 2215).

B) In den J. 1331 und 1332. Vgl. Werunsky, Geschichte Karl's IV., Bd. 1 S. $31 \cdot \mathrm{ff}$.

7) Vgl. Werunsky, Der erste Römerzug Kaiser Karls IV. (Innsbruck 1878). S. 318. 
auch die Städte unterliegen ${ }^{1}$ ). Sehen wir $z u$, welchen Verlauf die Dinge genommen haben.

Luna war seit dem 11. Jahrhundert in seiner städtischen Entwicklung hinter seinen unmittelbaren Nachbarn Luca und Pisa sehr zurückgeblieben. Doch erscheint es im 12. Jahrhundert noch als mit Mauern umgebener Ort²), unter dessen Gebäuden das aús der römischen Zeit stammende Amphitheater besonders hervorgehoben wird ${ }^{3}$ ). Auch die kleineren Häfen des Golfes, der speciell nach Luna benannte und der von Amelia (an der Mündung der Macra), jenseits dessen das Vorgebirge Caprione lag; dann der Mons Illicis mit seinem Hafen (Lerici ${ }^{4}$ ). Man redete hie und da sogar noch in alterthümlicher Weise rom Meer von Luna $^{5}$ ).

Die Cathedralkirche von Luna, die Marien geweiht war, entbielt als kostbarste Reliquie eine Ampulla mit Blutstropfen Christi, womit man freilich gegenüber dem, sacer vultus" der Erlösers in Luca nicht aufkam. Doch wurden hieher zahlreiche Schenkungen gemacht6). Von Bedeutung für die Frequenz von Luna war, dass es das Marktrecht besass ${ }^{7}$; an den Markttagen liefen auch die Opfergaben am reichlichsten ein.

Da ereignete es sich, dass im Laufe des 12. Jahrhunderts die Malaria an dieser Küste sich immermehr geltend zu machen begann,

1) Paradis. XVI, 73. Dante hat diesen Gedanken vielleicht dem Rutilius Namatianus de red. I, $413 \mathrm{f}$. entnommen, der ihn mit Bezug auf Populonia äussert. (Die Textüberlieferung beruht auf einem Codex Bobiensis).

2) So in der Urk. des Kaisers Friedrich I. vom J. 1185: civitatem Lunensem cum fossatis et suburbiis et suburbanis suis, cum ripa et teloneo et mercato - et plateam quae est inter murum civitatis et mare . . . .

s) Ebenda: aedificium quod circulum vocatur, aut arena. Vgl. Friedländer, Sittengesch. Roms II, 522.

4) Friedrich I. im J. 1183 (St. 4364): ripam Lunensis portus atque portus Ameliae. Das Privileg von 1185 nennt montem de Caprione; montem Illicis cum portu.

5) Gervasius Tillebur. in den „Otia imperialia" (Mon. Germ. Script. XXVII p. 387), allerdings in einer Erzählung, die in die Karolingerzeit zurückführt: sad plagam pelagi Lunensis «. Vgl. Davidsohn, Gesch. von Florenz I 66 Anm. 1, der daraus die Erinnerung an Stadtkämpfe zwischen Luca und Luna Ende des 8. oder Anfang des 9. Jahrhunderts deduciren will.

6) Gervas. Tillebur. 1. c. Vgl. Ughelli $I^{2}$ p. 840 : Schenkung an die Marienkirche vom J. 1085: „in loco Lunae 1124 : episcopatus sanctae Mariae; ecclesia s. Mariae Lunensis.

7) In J. 963 (St. 325) bestätigt Otto I. dem Bischof: cortem de Luna cum mercatis et pertinentiis suis. 
in Folge dessen die Bevölkerung nach der umliegenden Hügelgegend sich verzog, wo wenige Millien von Luna entfernt Sarzana gelegen war.

Dieses wird schon früher genannt; es ist wahrscheinlich das Surianum der Pippin'schen Verheissung ${ }^{1}$ ). In den Urkunden des 11. und 12. Jahrhunderts heisst es "burgum" oder "castrum" Sarzana. Der Bischof von Luna hatte hier einen Hof mit Zubehör, wo wir schon im 11. Jahrhundert wichtige die Kirche von Luna betreffende Rechtsgeschäfte abgewickelt sehen ${ }^{2}$ ). Hieher verlegte sich auch der Marktverkehr, seit die üble Luft von Luna diese Stadt in Verruf brachte ${ }^{3}$ ), und es überhaupt nur wenige mehr dort aushielten.

So entsprach es nur den thatsächlichen Verhältnissen, wenn Kaiser Friedrich I., als die Organisation Italiens ernstlich in Angriff genommen wurde, auch die Stellung yon Sarzana neu regulirte. Es geschah dies durch ein Privileg vom 4. November 1163, nachdem dex Vertrauensmann des Kaisers Rainald von Dassel sich von dem Stande der Dinge persönlich überzeugt hatte4). Das burgum Sarzana wurde unmittelbar in den Schutz des Reiches übernommen ${ }^{5}$ ) und bekam Rechte, wie sie die grossen Städte der Nachbarschaft seit denı vorigen Jahrhundert schon hatten. Es wurde verboten innerhalb des Ortes

1) So schon Cluverius, neuerdings Ficker. Vgl. Dove (1894) S. 203 Anm. Man nimmt an dass "Surianum" für "Sergianum" verschrieben sei. Aus diesem sei Sarzana (Sergiana) entstanden. Anders Ketterer im Hist. Jahrb. 1900 S. 443 f.

2) Im J. 1085 (Ughelli I2 841): ,Actum burgo Sarzana 1137:, actum in synodo habita in ecclesia s. Andreae de Sarzanas. In dem Privileg für den Bischof von Luna 1185 heisst es: castrum de Sarzana cum curte et districtu suo, et villas quae ad ipsam curtem pertinent et herbaticum eiusdem curtis burgi de Sarzana et iustitiam eius et mercatum .... .

s) Sie heisst, maledicta a bei Gervas. Tillebur. l. c. Ebenso im britischen Itinerar Mon. Germ. Script. XVII p. 131. Vgl. die Narratio in der Translationsbulle P. Innocenz III. vom J. 1204: cum Lunensis civitas - sic suos habitatores devoret et consumat, quod pauci vel nulli commorentur in ea, nec sit populus qui iura et libertates ecclesiae vestrae protegat et defendat.

4) Die Annal. Pisan. berichten ad a. 1163, dass Rainald von Pisa aus, wo er am 20. Sept. dieses Jahres weilte, perrexit ad Serzanam, ibique parlamentum cum consulibus civitatum Tuscie fecit. Von da kehrte er in die Lombardei zurück. Ueber die Thätigkeit Rainalds von Dassel in Tuscien überhaupt vgl. Ficker, Ital. Forschungen II S. 138. Davidsohn, Forschungen zur Gesch. von Florenz I 100. Das Privileg bei Ficker, IV n. $133=$ (mit Besserungen) Winkelmann, Acta imp. ined. II (1885) n. 1235 p. 887 ff. Vgl. Scheffer-Boichorst, Zur Gesch. des 12. und 13. Jahrhunderts S. $168 \mathrm{ff}$.

5) Burgum nostrum Sarrazanum, qui videlicet est in comitatu Lunensi, cum burgensibus eius omnibus et cunctis eorum pertinenciis sub nostram tutelam ac protectionem perpetuam recipimus et specialem nostram ac sacri imperii cameram eum esse praecipimus. 
einen Turm oder eine Befestigung zu bauen, die nicht zum gemeinen Nutzen sei ${ }^{1}$ ). In Betreff des Zuzugs aus der Umgebung wurde erklärt, dass freie Leute sich ohne weiteres ansiedeln dürfen und dann dieselben Rechte geniessen, wie die bisherigen burgenses' ${ }^{2}$ ). Nur bezüglich der Hörigen und Frohndienstpflichtigen werden Schwierigkeiten gemacht, wie das ähnlich aus deutschen Stadtrechten bekannt ist.

Die weiteren Bestimmungen des Privilegs zielen darauf ab Sarzana, das bisher von Luna in mehrfacher namentlich auch wirtschaftlicher Beziehung ablängig gewesen war, davon zu emancipiren.

Die „burgenses" haben künftighin weder am Meer noch im Fluss Macra eine Verkehrsabgabe zu entrichten ${ }^{3}$ ), wodurch sie etwa hätten chicanirt werden können, wie die Lucchesen von den Pisanern. Auch wird festgestellt, dass die Sarzanenser in den umliegenden Wäldern dasselbe Niessrecht haben sollen wie bisher ${ }^{4}$ ).

Es folgt die für das Gedeihen des Ortes entscheidende Bestimnung über den Markt. Die Sarzanenser bekommen einen Wochenmarkt, der an jedem Samstag abzuhalten ist ${ }^{5}$ ). Der Ort hiezu soll von den gegenwärtigen Consuln von Sarzana nach ihrem Gutdünken festgestellt werden. Wir lernen hier die Verwaltungsmänner, die ja auch sonst in nichtstädtischen Gemeinden des toskanischen Gebietes als consules vorzukommen pflegen 6 ), des Näheren kennen; sie haben über den Markt zu verfügen. Dabei wird ausdrücklich bemerkt, dass den Sarzanensern hinsichtlich dieses Marktes weder in Luna noch an einem anderen Orte des Comitates von Luna ein Hindernis in den Weg ge-

1) Ut nulla turris vel aliqua alia munitio in burgo illo levetur, nisi que ad communem totius burgi utilitatem. Vgl. Bonaini, Statuti di Pisa p. 16 : Friedensstiftung des Bischofe Daibert (1088-1099): Bestimmungen über die zulässige Höhe der Häuser. Ebenda das, breve consulum Pisanae civitatis vom J. 1165 .

2) Si quis etiam liber homo qui non sit servus aut angariarius alicuius, habitator illius burgi effici voluerit, libere ac secure ad eum veniat ipsumque inhabitet et speciali nostra protectione sicut ceteri burgenses ipse cum omnibus rebus ac possessionibus suis perfruatur.

s) ut neque in littore Lunensi nec in Macre flumine pedaticum vel datium aliquod tribuant.

4) nullusque ex convicinis eorum in nemoribus seu in silvis, quibus uti consueverunt, aliquid eis iniuste auferre praesumat.

5) Mercatum quoque solemne - Sarrazanensibus quolibet die Sabbati con. cedimus, et sit locus mercati, ubi presentibus eorum consulibus magis congruum visum fuerit.

6) Vgl. R. Davidsohn, Ueber die Entstehung des Consulats in T'oscana. Hist. Vierteljahrschrift III (1900) S. 1-26. Die Consuln begegnen in den kleinsten dändlichen Kreisen der Comitate von Florenz, Pistoja u. s. w. 
legt werden dürfte ${ }^{1}$ ). Man sieht: Luna rivalisirt zu dieser Zeit noch mit Sarzana, es sind Gegenbestrebungen vorgesehen.

Von der Gerichtsbarkeit ist dabei nicht die Rede ${ }^{2}$ ); als zwanzig Jahre später (1183) der Bischof die Grafengewalt überkam, stand ihm das öffentliche Gericht $\mathrm{zu}^{3}$ ), während er über seinen Hof und die daran hängenden Besitzungen kraft seiner Immunität waltete.

Bereits waren Bischof und Capitel entschlossen, das heruntergekommene Luna zu verlassen und mit dem Bischofsitz nach Sarzanz zu übersiedeln ${ }^{4}$ ). Am Meer hatte man seit der Uebermacht von Genua und Pisa keine Interessen mehr, der Verkehr zu Land von Genua her war geringfügig ${ }^{5}$ ), der mit dem Apenninenpass aber liess sich von Sarzana aus besser übersehen und leiten - gerade dadurch war dieses

1) ut neque Lune neque in aliqua parte comitatus Lunensis forum aliquod fat, per quod istud impediri valeat. - Ut nullus mortalium forum illud impedire seu perturbare aut homines illud visitantes vel inde redeuntes aliquo modo audeat violenter offendere.

2) Kaiser Friedrich I. überliess in Tuscien den Slädten nur ausnahmweise (z. B. an Pisa) die Gerichtsbarkeit. Der Stadt Luca entzog er sie. Vgl. SchefferBoichorst, Friedrichs I. letzter Streit S. 75. Davidsohn, Forsch. I 99 f.

3) Das stellten die Sarzanesen in ihren Streitigkeiten mit dem Bischof freilich in Abrede. Im J. 1219 machte der Vortreter des Bischots geltend: , quod Lunensis episcopus pro episcopatu est comes et iudex castri et burgi Sarzanae, et quarumdam terrarum Lunensis episcopatus ex concessione imperatoris". Im: Gegensatz dazu praetendirten die Sarzanesen:, quod marcha de Luna est marcha de Malaspina, et de Massa; et suorum consortum; et alius comitatus vel marchia non est in Lunisiana". Bei Muratori Ant. Est. p. 260. Vgl. Ficker, Forschungen I S. 253. Die Regel war allerdings, dass da, wo die Markgrafschaft entwickelt ist, Verleihungen der Grafschaft an die Bischöfe nicht vorkommen.

4) Die folgende Translationsgeschichte ist nicht ohne Interesse, wenn man zum Vergleiche analoge Fälle heranzieht, z. B. die Gründung von Aquila, womit gleichfalls die Verlegung eines Bischofsitzes (von Furcona oder S. Maximi auf die neuerbante Kathedrale S. Maximi et Georgii) verknüpft war. Auch kam die rivalisirende Competenz von Imperium und Sacerdotium zum Ausdruck. Vgl. Winkelmann, Reg. Gregors IX. n. 6780. 6785. Böhmer-Ficker, Reg. Conrads IV. n. 4626 a. 4627.4701 b. So zog sich die Sache durch 28 Jahre hin; schon 1229 geschahen die vorbereitenden Schritte, 1254 die Gründung, 1257 die Verlegung des Bischofsitzes. - Man vgl. auch die im J. 1263 von Manfied verordnete, $\mathrm{Zu}$ răckverlegung * der Stadt Sipontum (wo ein Erzbischof seinen Sitz hatte) wegen der dort herrschenden schlechten Luft auf den benachbarten Ort, wo sie bereits einmal gestanden hat und wo gute Luft ist. Böhmer-Ficker, Reg. 4749.

5) Im J. 1171 geben die Genuesen dem Christian von Mainz das Geleite bis Luna. Annal. Januens. p. 90. Im J. 1178, als Kaiser Friedrich I. Pisa und Genua besuchte: nec mare nec stagna tetigit tunc gens Alemanna, sed per Serzana subiit montana Lovangna (Lavagna). Gotifred. Viterb. Gesta Frid. v. $1081 \mathrm{f}$. 
emporgekommen und hatte die Aufmerksamkeit der neuerdings zielbewasst vorgehenden Reichsregierung auf sich gezogen ${ }^{1}$ ).

Als im J. 1187 Papst Gregor VIII., um zwischen Genua und Pisa wegen des bevorstehenden Kreuzzuges zu vermitteln, in die Gegend kam (er weilte am 9. Dezember dieses Jahres in Luca, rom 10. bis 17. Dezember in Pisa) wurde ihm die Sache von Luna vorgetragen und der Papst gieng, da die kleine Bischofstadt von den Durchreisenden bereits zur Zielscheibe des Spottes gemacht wurde, darauf ein; er bewilligte die Verlegung des Bischofsitzes von Luna nach Sarzana und schenkte zum Bau der Kirche einen geweihten Stein ${ }^{2}$ ).

Aber bevor noch die nöthigen weiteren Formalitäten zum Abschluss gekommen waren, starb Gregor VIII. am 17. Dezember 1187 zu Pisa und die Translation kam ins Stocken, da man mit dem Tode jenes Papstes auch die von ihm ertheilte Erlaubnis für erloschen hielt ${ }^{3}$ ).

Erst als man sich sechzehn Jahre später an Innocenz III. wendete, wurde die Angelegenheit endgiltig geregelt: der Papst bewilligte durch eine Bulle vom 21. März 1204 dem Bischof und dem Capitel, den Bischofsitz (mitsammt den dort verehrten Reliquien) von Luna nach Sarzana zu verlegen ${ }^{4}$ ).

Der Ort Luna blieb noch eine Zeitlang Strassenstation, wie denn das Wegesystem der römischen Zeit bis dahin keine Aenderung er-

1) Vgl. auch die Translationsbulle von 1204, wo mit Beziehung auf die Aktion des J. 1187 gesagt ist: ut ad locum populosum, Sarzanam nomine, episcopalem cathedram transferetis. Aber schon 1202 hatte die wehrfach erwähnte Einigung zwischen dem Bischof von Luna und den Markgrafen Malaspina (Lïnig II, 253) ihren Abschluss gefunden, in camera castri de Sarzanac.

2) Vgl, die Narratio der Translationsbulle von 1204: tempore sanctae memoriae Gregorii papae, praedecessoris nostri, usque adeo proposuistis fuisse processum, quod cum.ille per partes illas transitum faceret, ipsius translationis licentiam - concessit, et pro construenda ecclesia dedit vobis - lapidem benedictum.. (Vgl. Davidsohn Forschungen I 184 über das von P. Alexander IlI. dem Bischof von Faesulae gewährte Privileg, seinen Sitz nach dem castrum Figlinense zu verlegen).

9) 1. c. quia post paucos dies idem praedecessor noster viam fuit universae carnis ingressus, credentes mandatum eius in ipso obitu exspirasse etc. Bei Jaffé geschieht dieser Vorgänge nicht Ejwähnung; auch nicht in der Neubearbeitung der Regesten.

4) Potthast, Reg. n. 2161. Innocentii opp. ed. Migne II, 306: (Waltero) episcopo et capitulo Lunensibus. Vgl. Gervasius Tillebur. in den ,Otia imperialia * (Monum. German. Scriptor. XVII p. 387, geschrieben bald nach 1212): Est autem castrum Lunensis episcopi quod sancte Marie de Saracenai (d. i. Sarzana) dicunt, ubi ampullam (mit den Blutstropfen Christi) vidimus et tractavimus, ubi (etiam) episcopatum in maledictionem Lunensiun translatum audivimus. 
fahren hatte. So erscheint Luna in den Itinerarien der Zeit, so bei Salimbene, der gelegentlich von einem Franziskanerkloster spricht, das zwischen Luca und Pisa gelegen war, am Wege der nach Luna führt1).

Aber officiell galt Luna von da an als ,zerstörte Stadt", wie es z. B. im J. 1263 vom Papst Urban. IV. ausdrücklich bezeichnet wird2). Keine hundert Jahre später fabelte man von der Sündhaftigkeit, durch welche der Ruin einer so angesehenen aus den wieder viejgelesenen Classikern bekannten Stadt (man nannte sie jetzt "Luni“) veranlasst worden sei $^{3}$ ). Erst die im 15. Jahrhundert mit Cyriacus von Ancona einsetzende Alterthumswissenschaft brachte wieder exaktere Kunde; späteren Forschern, wie dem vortrefflichen Cluverius kamen gleichwohl Zweifel über die Lage der Stadt, die er nach Lerici, unmittelbar ans Meer versetzen zu müssen glaubte; ein Irrtium, den erst seine Nachfolger auf dem Gebiete der historischen Landeskunde ltaliens corrigirt haben ${ }^{4}$ ).

Sarzana, das als Bischofsitz seinen Charakter als quasistädtisches Gemeinwesen befestigte ${ }^{\tilde{5}}$ ), wusste unter den folgenden Kaisern, namentlich. unter Friedrich II,, sich als "besondere Kammer des Reiches" zu behaupten; es wurde von jeder fremden Gerichtsbarkeit für befreit erklärt und blieb dem Reiche direct unterstellt ${ }^{6}$ ).

Mit den Bischöfen, die hier residirten, hatte Sarzana manchen Strauss zu bestehen, es zog sich auch päpstliche Verwarnungen $\mathbf{z u}^{7}$ ),

1) Salimbene p. 101 (ed. Parmens.): quod erat inter Lucam et civitatem Pisanam, per viam quae vadit ad civitatem Lunensem. Im Itinerar der britischen Kreuzfahrer zu Ende des 12. Jahrhunderts (Mon. Germ. Scriptor. XXVIl p. 131) geht es , per Lune maledictam civitatem episcopalem et per sanctam Mariam de Sardena (d. i. Sarzana).

2) Urban IV. am 1. Dez. 1263: locus de Sarzana, in quo Lunensi civitate destructa capitulum Lunensis ecclesiae commoratur. Es muss so in den officiellen Listen eingezeichnet gewesen sein. Mon. Germ. eplae s. XIII tom. 3 p. 557.

3) Vgl. Villani, Cron. I, 50: La città di Luni la quale è oggi disfatta diserta la contrada e mal sana. Aehnlich noch im 14. Jahrhundert Petrarca und Fazio degli Uberti (Dittamondo III, 6).

4) Cyriacus von Ancona besuchte die Ruinen von Luna im J. 1442. Ausser Cluverius vgl. auch Alberti, descrittione di tutta Italia (ed. Venezia 1557) p. 24.

5) Im J. 1202 werden , Consules, milites et populus - de burgo et de castro Sarzani" genannt. Lünig Il, 253.

6) Im J. 1226. Ficker, Forschungen IV, n. 321. Winkelmann, Acta n. 285.

7) Vgl. Ughelli $I^{2}$ p. 850 f. zu den J. 1200, 1219 (Schiedsspruch eines Pisaners), 1230. (Uebereinkommen des Bischofs Wilhelm mit den homines Sarzanae). Im J. 1233 April 7 Gregorius IX. papa communitatibus comitatus Lunensis mandat, ut coniurationes suas solvant et (Wilhelmo) episcopo Lunensi reverentiam exhibeant. Mon. Germ. Epistol. s. XIII, tom. 1 p. 418 . Winkelmann Keg. Gregors IX., n. 6952. Derselbe, Jahrb. Friedrichs II., Bd. 2, 433 A. 3. 
ohne dass diese etwas genützt hätten. Im Uebrigen wurde Sarzana ein wichtiger Verkehrsort 1). Von Ludwig dem Bayer erwirkte es sich die Erlaubnis, Eingangszölle gleich den anderen Städten Tusciens zu erheben; zugleich erstreckte der Kaiser das Gebiet Sarzana's auf einen Umkreis von zwei Millien und bis zum $\mathrm{Meer}^{2}$ ).

War auf diese Weise die Stadt Luna zu Grunde gegangen, so blieb doch dem Gebiet derselben, im Umfange des Bisthums und des einstigen Comitats, der Name des Lunensischen oder der Lunesana ${ }^{3}$ ). Daneben ist in der hergebrachten Weise von der "dioecesis Lunensis" die Rede, denn die Bewilligung zur Aenderung des Namens mit Rücksicht auf den neuen Sitz ist ihr erst im 15. Jahrhundert zu Theil geworden, nachdem es einem Sarzanesen gelungen war, sich auf den Stuhl Petri zu schwingen ${ }^{4}$ ).

In politischer Hinsicht zerfiel das Gebiet von Luna in eine Reihe von Territorien. Von den "partes Lunisane" wurden die "partes Malaspinae" unterschieden. Ferner kamen als selbständig dastehende durch kaiserliche Privilegien constituirte Gemeinden Sarzana und Pontremoli in Betracht5), beide ans ihrer Lage zum Apenninübergange von Cisa ihre Bedeutung schöpfend.

1) Vgl. die Ann. Plac. ad a. 1247, wo König Enzio die Verbindungen zwischen Tuscien und Lombardien wiederherstellte - über Pontremoli und Filatiera (wo ein rebellischer Malaspina sass): unde aperta fuit via euntibus et redeuntibus Sarzanam. Vgl. auch mein ,Bobbio* S. 550 A. 1: Der, mons Bardonis* volk von Kaufleuten und Saumthieren. Ann. Parmens. mai. ad a. 1277: comune Parme missit Sarzanam ad deducendum furmentum, emptum per comune in Apulia.

2) Ludwig der Bayer im J. 1328 November 26 (bei Winkelmann, acta imp. inedit. II n. 500) : officialibus, consilio et comuni terre Sarzane Lunensis diocesis .... duo milliaria circum Sarzanam - et ultra versus mare, id quod est a strata Romea inferius usque ad aquam Parmignole cum nemoribus Caprioni....

3) Man findet verschiedene Formen. Im J. 884 in der Urkunde für S. Caprasio heisst es , in loco et finibus Lunensis "; finibus Lunianense'; , in iam dictis locis Lunianenses. - Im 13. Jahrhundert: Lulixana (Ann. Parmens. maior. ad a. 1243), Lunexana, Lurexana (Ann. Januens. ad a. 1268), auch Nuxedana (Annal. Placent. ad. a. 1271 p. 292 der ParmenserAusgabe). Lunesana bei Huillard-Bréholles 5, 6ł1. Vgl. Ficker, Forschungen II, 506.

4) Ughelli I2 p. 85.5. Seitdem hiess das Bisthum Luna-Sarzana. Papst Nicolaus V. (1447-1455) war der Sohn eines Arztes aus Sarzana. Dekretirt wurde die neue Benennung und zugleich die Erhebung Sarzana's zur Stadt 1465. Vgl. Sforza, P. Nicolaus V. Heimat, Familie und Jugend, (deutsch Innsbruck 1887).

5) Annal. Placent. ad a. 1268: in Pontremoli et Sarzana et Lunensi. Böhmer, Acta imp. sel, n. 1071 : Otto IV. verpflichtet sich 1210 Juni 3 den Pisanern wegen Portovenere gegen Genua u. s. w, Die Verpflichtungen werden auch auferlegt. 
Pontremoli wird als ein fester Punkt bezeichnet, nm den wiederholte Kämpfe ausgefochten wurden ${ }^{1}$ ), sowohl von der Reichsgewalt wie von den zunächst interessirten Communen. Das Reich suchte sich des beständigen Durchzuges zu versichern, indem im J. 1167 durch Friedrich I. denen von Pontremoli gegen einen jährlich nach Pavia zu zahlenden Zins die Regalien verliehen wurden²). Seitdem erscheint Pontremoli in den Verträgen der Magnaten als ein für sich stehendes Glied in der Organisation des Lunensischen Gebietes neben dem Bischof und den Markgrafen ${ }^{3}$ ). Im J. 1226, bestätigte Kaiser Friedrich II. denen von Pontremoli ihre Besitzungen mit genauer Angabe der Grenzen derselben: wir ersehen daraus, dass die Communen

unter anderen: episcopo Lunensi, consulibus vel rectoribus Pontremulensibus et marchioni Malespine et omnibus rectoribus locorum Lunisciane. - Im J. 1233 schreibt Papst Gregor IX. „communitatibus comitatus Lunensis «; im J. 1267 spricht Clemens IV. von den, homines castrorum Lunensis sedis, qui quondam Manfredo faverint c. Es war locus de Sarzana - et magna pars dioecesis Lunensis. Mon. Germ. epist. s. XIII tom. 1 p. 418 ; tom. 3 p. 673.

1) Vgl. Otton. Frising. chronic. VII, 14 über den Römerzug Heinrichs V. in Dezember 1110 (nachdem im Oktober die Grossgräfin Mathilde in Pontremoli geweilt hatte (Overmann S. 81 n. 106): Appenninum transcendit, oppidumque quod Pons Tremulus vocatur natura locorum ac altissimis turribus munitissimum, transitum prohibens, expugnavit et cepit. Vgl. auch Ekkehardi Uraug. chronic. ad a. 1110 M. G. Script. V1 244. Donizo, vita Mathildis II c. 18: Francigenam stratam tenuit rex, pace peracta, transivit certe tunc incipiente Decembre Montem Burdonis. Im J. 1133 zog Lothar von Supplinburg diesen Weg. Vgl. Bernhardi, Lothar von Supplinburg S. 465. Ueber den Vorfall von 1136 s. oben S. 223. Ueber den Rückzug Kaiser Friedrichs I. im J. 1167 und die Haltung von Pontremoli vgl. Gotifred. Viterb. gesta Frid. v. $713 \mathrm{ff}$. Ad pontis Tremuli veniunt montana dolosa. Zuerst ist von Pontremoli in der Urk. Heinricbs IV. für die Söhne des Markgrafen Albert Azzo II. im J. 1077 (St. 2986) die Rede. Das Haus Este, das von den Otbertinern herstammte, besass damals, in comitatu Lunense Pontremulum, Filateram u. s. w. Im Allgemeinen vgl. Sforza, Memorie e doeumenti per servire alla storia di Pontremoli (Luca 1885).

2) Ficker, Forschungen IV n. 142: donamus hominibus de Pontremulo omnia nostra regalia, quae habemus ab ambe (ambitu?) curic usque ad Alpes et a Monte Cironis usque ad Montem Rotondum et usque ad Incisam, usque ad Ligno. Districtus vero, videlicet bannum, hostem et cetera nostra regalia et quatuordecim denarios de passagio nostro imperiali, quod coligitur in Pontremulo, eo tamen expresso tenore, quod ipsi singulis annis debent persolvere nobis vel nuntiis nostris apud Papiam - quinquaginta libras imperialium etc. Alpes similiter eis concedimus.

s) So im Laudum des J. 1202 (Lünig II, 253): sowoll der Bischof von Luna wie die Markgrafen haben mit Pontremoli ein Abkommen, das von ihrer Einigung nicht berührt werden soll. Unter denjenigen, welche den Vertrag beschwören, findet sich auch genannt: populus et milites de Pontremulo. 
von Placentia und Pontremoli mit dem Gebiete der Markgrafen Malaspina zusammenstiessen ${ }^{1}$ ).

Wir haben bereits früher gesehen, wie Kaiser Friedrich II. sich seit 1239 des burgums von Pontremoli (neben dem wie bei Bardi das oppidum sich selbständig entwickelte) versicherte ${ }^{2}$ ). Im J. 1249 schenkte König Wilhelm Pontremoli an die Fieschi, die es 1268 in Linverständnis mit einem Malaspina an Karl von Anjou auslieferten, der hier den Konradinern den Pass sperrte ${ }^{3}$ ). Am Ausgang des 13. Jahrhunderts sehen wir die Communen von Parma und Iuca, auch die Malaspina um den Besitz von Pontremoli sich streiten ${ }^{4}$ ). Hingegen bestätigte Kaiser Heinrich VII. 1313 den Fieschi Pontremoli unter Vorbehalt des Besatzungsrechtes und anderer Leistungen an das Reich5), während Ludwig der Bayer 1329 denen von Pontremoli unter Berufung auf das Privileg Friedrich's II. wieder die Reichsunmittelbarkeit verbriefte $\left.{ }^{6}\right)$. So stand immer ein Rechtstitel gegen den anderen und die Machtverbältnisse entschieden. -- Ausser Sarzana und Pontremoli sind im Lunensischen Gebiete noch zwei Orte zu nennen, die einige Bedeutung gewannen, nemlich Carrara und Massa.

Carrara lag bei den Steinbrüchen, von denen es wie es scheint auch den Namen hat 7 ), es erbte den Ruhm von Luna in Bezug auf den Marmor, der auch im Mittelalter geschätzt war; daher sich in der Nähe eine ansehnliche Niederlassung erhielt, wo der Bischof einen Hof

1) Ficker, Forschungen IV, n. 320 (Pontremoli 1226 Juli) : videlicet a fauce Gise et a fauce montis de Cirono infra versus burgum Pontistremuli, et ab utroque flumine Caprie supra, sicut dividuntur terre marchionum Malespine a terris communis Pontistremuli per illa duo flumina, et a Monte Rotondo et a Monte Gottari citra versus eundem locum Pontistremuli; item a loco illo citra, qui dicitur Capra mortua, et a flumine Tarodane citra, sicut dividuntur terre Placentinorum a terris comunis Pontistremuli; et a Cruce ferrea infra versus eundem locum Pontistremuli. Unter den Zeugen befindet sich C. marchio Malaspina.

2) Vgl. Ficker, Forschungen II S. 506.

3) Die Annal. Placentini ad a. 1268: (Karolus) facto pacto cum Ysnardo Malaspina et comitibus de Fisco qui tenebant Pontremullum, dedebant sibi fortiam Pontremulli. Andererseits war ein Bruder des Ysnard Malaspina, Namens Bernard, Vicar König Manfreds gewesen. Vgl. Winkelmann, Reg. Clemens IV., n. 9763 (1267 März 1).

4) Vgl. die Annal. Parmens. maior. ad a. 1287. 1293.

5) Ficker, Forschungen III S. 454.

$\left.{ }^{6}\right)$ Ficker, Forschungen IV n. 513.

7) Vgl. Egli, Nomina geographica p. 172. Keltisch Kaer, Ker, cair(e) = Stein, Fels. Französisch carrière, Steinbruch. Auch Kiepert, Lehrbuch der alten Geogr. S. 406 theilt diese Ansicht. Ueber die Geschichte von Carrara handelt Repetti, sopra l'Alpe Apuana p. $185 \mathrm{f}$. 
hatte, und der Graf Amtstage abhielt1). Im J. 1202 war Carrara wie Sarzana constituirt; es werden als die massgebenden Faktoren des Gemeinwesens "consules, milites et populus de Carraria“ genannt²).

Der Ort Massa verdankt seinen Namen ohne Zweifel wie so viele andere dem Umstand, dass im Lauf der römischen Kaiserzeit durch Einschlachtung mehrerer "praedia" oder "fundi" eiu grösserer Complex zu Stande kam. Eine solche Massa konnte nur durch nähere Ortsbestimmung gekennzeichnet werden, danach unterschied man Massa Trabaria, Massa Firminiana (in der Nähe von Ravenna und Ferrara), Massa Ferrariensis, Massa Fiscaglia, Massagrossa (d. i. Massarosa, westlich von Luca), Massa Pisana ${ }^{3}$ ), endlich Massa maritima, wohin der Bischofsitz von Populonia verlegt worden war $^{4}$ ), und viele andere. Eine Confusion ergab sich nur dann, wenn das unterscheidende Distinctiv weggelassen wurde ${ }^{5}$ ). So war es auch bei jener Massa ${ }^{6}$ ), die zum Unterschiede von den anderen als „Massa Lunensis“ bezeichnet wurde ${ }^{7}$, während man oft auch hier Massa kurzweg sagte.

Am ehesten konnte diese Lunensische Massa mit jener bei Luca, bei Pisa, endlich mit der Massa an der tuscischen Maritima verwech-

1) Im J. 998 datirt Markgraf Otbert, in broilo de Carrara . S. oben S. 216 A. 3. Vgl. Bresslau, Konrad II. Bd. 1, S. 427. - Plebs s. Andreae de Carraria; plebs s. Andreae im J. 1137, wo Bischof Gottfried von Luna dieser plebs eine Schenkung macht (Ughelli). Im J. 1151: ecclesia et plebs \&. Andreae de Carraria. Im J. 1185 bestätigt Friedrich I. dem Bischof: curtem Carrariae cum Alpibus, lapicidinis etiam marmorum ete.

2) In dem Laudum von 1202 bei Lünig II, 253.

3) Vgl. Regesten Conradins 4852 a. Südlich von Luca.

4) Populonia wird schon vor Luna, civitas destructa genannt. Vgl. 1143 Papst Cölestin II. für das Kloster S. Salvatoris et b. Quirici Populonie. Er bestätigt unter den Besitzungen auch montem civitatis destructae, quae antiquitus Populonia vocata est. Ughelli III² p. 711 f. Ughelli p. 715 meint, dass der Nachfolger des Bischofs Walter von Luna (1213), Marzuchius, mit dem gleichnamigen Bischof von Massa, der dort einige Jahre früher erscheint, identisch sei. Marzuchius wäre also von Massa (maritima) nach Luna versetzt worden.

5) Vgl. Overmann, Die Besitzungen der Grossgräfin Mathilde, Regesten, n. 86, 107, 110. Datirt aus ,Massa. Aber (bemerkt der Verf.), es gibt in Lombardien und Tuscien eine ganze Reihe von Orten, die den Namen Massa führen". Ueber Massa Lunensis handelt Repetti ]. c. p. $215 \mathrm{f}$.

в) Vg1. die Annal. Placent. ad a. 1268. Die Conradiner kommen übers Gebirge usque Sarzanam. Deinde ceperunt Massam equitando sine aliqua contraditione ad civitatem Pisanam.

7) Der Ausdruck ,Massa Lunensis \& ist auch im 14. Jahrhundert geläufig, vgl. Memorie di Luca I, 368 zum J. 1348. Bei Lünig, Codex Ital. dipl. II 2231 ist von Streitigkeiten zwischen Luca (das einen Küstenstrich am Meer besass) und Massa Lunigiana die Rede, die 1599 zur Verhandlung kamen. 
selt werden. Massa maritima, das schon in der Langobardischen Zeit so genannt wird ${ }^{1}$, war in den Machtbereich der Pisaner gerathen, seitdem diese die Herrschaft zur See hatten, ebenso wie die Inseln Elba, Capraria, Gorgona, Planasia, Corsica. Neben den pisanischen Einflüssen kamen aber in dieser Massa auch die des Bischofs von Populonia-Massa und die des Pfalzgrafen von Tuscien in Betracht, die neben einander vom Reiche anerkannt waren ${ }^{2}$ ). Als im J. 1137 Pisa von Papst Innocenz II. zum Erzbisthum erhoben wurde, bekam es neben drei Bischöfen aut Corsica und zwei Bischöfen auf Sardinien auch den von Populonia di Maremma (d. i. eben Massa maritima) als Suffragane untergeordnet, worauf die Pisaner offenbar ebenso grosses Gewicht legten, wie die Genuesen aut die Unterordnung des Bischofs von Brugnato unter ihren Erzbisch of ${ }^{3}$ ).

In der Massa Lunensis erscheint der Bischof von Luna als Besitzer, ebenso die Markgrafen Malaspina4). Das war für die Folgezeit entscheidend, da der Bischof den städtischen wie den territorialen Gewalten gegenüber schliesslich überall den Kürzeren zog.

Seit dem 12. Jahrhundert nennt sich ein Zweig der Markgrafen nach der „Massa Lunensis“, wo er seinen Sitz aufgeschlagen hatte ${ }^{5}$ ).

1) Holder-Egger, Langob. Regesten 114.

2) Vgl. Heinrich VI. im J. 1191 März 1 für die Pisaner: Concedimus etiam vobis castrum Massae et ipsam Massam. Im J. 1194 wird Massa (maritima) vom Reich an den Bischof gegeben. Ficker, Forsch. II S. 310, Anm. 10. III S. 413 zu § 156. Im J. 1195 April 27 (Stumpf acta ined. n. 196) bestätigt der Kaiser dem Pfalzgrafen Hildebrand von Tuscien alle durch Friedrich 1. verliehenen Rechte, überträgt dazn demselben alle Reichsrechte in Massa maritima (,in civitate Massa ). Im J. 1189 April 3 erklärt Heinrich VI, dem Papst Clemens unter anderem: item quod factum est in civitate Massanensi et pertinentiis in praeiudicium episcopi Massanensis, restituimus ipsi episcopo. Im J. 1267 gehört Massa maritima zu Pisa. Vgl. Ficker, IV p. 459: exceptis terris comitatus et districtus Pisani, in quo est et intelligatur Massa maritima. Im J. 1245 (Ficker IV n. 393): vicarius Maritime et comitatus Ildibrandeschi.

3) Die Inseln Sardinien und Corsica wurden auch von Reichswegen als zu Tuscien gehörig behandelt; so als Herzog Welf 1152 mit Tuscien belehnt wurde. 1158 wurden Reichsboten auch für diese Inseln bestellt. Ragewin, Gesta Friderici IV, 9. Vgl. Ficker, Forschungen $\amalg$ S. 226. Im J. 1164 gieng Opizo Malaspina als Bote des Kaisers nach Sardinien. Giesebrecht, D. Kaiserzeit V, 391.

4) Schon 963 bestätigt Otto I. (St. 325, Ughelli $\mathrm{I}^{2}$ p. 837) : cortem de Massa. In der Urk. von 1185 für den Bischof von Luna bestätigt Friedrich I.: curtem etiam quae supra Lunam dicitur Massa. Der Markgraf Opizo Malaspina hat 1164 quartam partem castri et curiae Massae.

5) Vgl. für das Folgende C. Desimoni, Sulle marche d'Italia e sulle loro diramazioni in marchesati. Seconda edizione (1898) p. $235 \mathrm{ff}$.: Sui marchesi di Massa in Lunigiana e di Parodi (dall' Archivio stor. Ital. X p. 324 ff.). 
Ein Seitenzweig nennt sich von Massa und Parodi (das letztere eine Burg zwischen Genua und Tortona). Der Stammvater dieses Seitenzweiges war Guillielmus „Franciscus" (oder „Francigena “, d. h. der Franzose), der in der Vertragsurkunde von 1124 genannt erscheint. Der andere Zweig stammte von Obertus, einem Bruder des Guillielmus -Franciscus" (beide waren Söhne des früher genannten Albertus "Rufus" ${ }^{1}{ }^{1}$. . Sie hatten die ererbten Besitzungen auf Corsica inne; daneben finden wir sie in Livorno begütert'2). Kein Wunder, dass sie mit Genua und mit Pisa in regem Verkehr standen. Die einen wurden durch ihre Interessen mehr zu Genua hingezogen. So renuntiirten im J. 1171 die Markgrafen Guillielmus und Rainer (Enkel des „Franzosen“ Guillielmus) zu Gunsten der Genuesen die directe Herrschaft auf Parodi, sie wurden auch für den Antheil ihrer Rechte aut Massa und die Inseln Vasallen von Genua ${ }^{3}$ ); zwei Jahre später erscheint Rainer als Bundesgenosse der Genuesen gegen die Malaspina ${ }^{4}$ ).

Ein Sohn des Obertus heisst Albertus "Corsus" ${ }^{4}$ ); dessen Sohn Guillielmus nennt sich von Massa. Dieser heiratet die Domicella Giorgia, Tochter eines Judex von Cagliari. Sein Sohn Guillielmus führt (um 1192) den Titel eines Judex von Cagliari, er ist Bürger von Pisa und vertritt dessen Interessen auf Sardinien ${ }^{6}$ ); er nennt sich wohl auch "von Massa und Cagliari“ ${ }^{7}$ ). Er hatte von einer Adelasia zwei Töchter, die eine Namens Benedicta, von der noch zu reden sein wird, die andere Agnes. Die Tochter der Agnes, die, domicella" Adelasia, heiratete in 7 weiter Ehe Enzio, den Sohn Kajser Friedrichs II., der dadurch „König“ von Sardinien wurde (1239) ${ }^{8}$ ).

Auch andere Markgrafen der "Massa Lunensis" sehen wir in Verbindung mit Luca oder mit Pisa. Im J. 1207 schwur Andreas marchio

1) S. oben S. 219.

2) Desimoni p. 238 f., 257 f. Er weicht in einzelnen Punkten von Muratori, Ant. Est. p. 260 ab. Im J. 1146 verkaufte Albert, Markgraf von Corsica, Sohn des quondam Brattaportata (ein Uebername des Obertus!), an einige Pisaner seinen Antheil (ein Drittel) des Castells von Livorno. Ughelli Ital. sacr. III, 391 (zum J. 1138): feudum de Livorno concessum irrationibiliter marchionibus Guillielmo Francigenae et eius fratribus.

3) Liber iurium reip. Genuensis I, 259, 266. Desimoni p. 237, 253. Unter den Inseln ist in erster Linie Corsica gemeint. Aber auch von Gorgona und Montecristo geht die Rede, p. 258 f. 261.

4) L. c. p. $251 ; 260$.

5). Liber iurium reip. Genuens. I, 277, 282.

6) Annal. Januens. Mon. Germ. XVIII p. 113. Vgl. Dove, de Sardinia p. 120.

7) Cod. Sardin. diplom. I, 303 ff. Vgl. Desimoni p. 237. 250. 260.

8) Vgl. Dove, de Sardinia p. 128 f., wo auch die späteren Schicksale dieser Adelasia erwähnt werdèn. Sie lebte noch 1255. 
Massae Lunensis, ein Enkel des Gưillielmus von Parodi 1), den Lucchesen den Treueid ${ }^{2}$ ); im J. 1218 verkauft er den Wegzoll (pedagium) zu Aulla an die Placentiner. Seine Söhne sind Guillielmus und Albertus, Markgraten der Massa Lunensis und von Corsica; sie wohnen in Pisa, mit welcher Stadt sie 125̃3 Vereinbarungen wegen Corvaja treffen ${ }^{3}$ ). Im J. 1260 wird ein Andreas marchio Masse et Corsice, Sohn des Guillielmus, erwähnt. Andere Nachkommen jener zwei Brüder, die den gleichen Titel führen, aber immer mehr herunterkamen, finden sich noch zu Ende des 13. Jahrhunderts und darüber hinaus.

Es ist bemerkenswert, wie diese Markgrafen von Massa als Mitjnhaber, der markgräflichen Gewalt im Gebiet von Luna erscheinen; sie unterhalten namentlich auch mit Sarzana stetige Verbindung ${ }^{4}$ ); sie werden hier gelegentlich gegen die Ansprüche des Bischofs ausgespielt $\left.{ }^{5}\right)$.

In Uebrigen verkörperte sich in diesen Markgrafen zum Theil die alte Bedeutung Luna's auch für die Inseln. Da in ịhrem Titel Luna, Corsica, Sardinien genannt erscheinen, ist es kein Wunder, dass als Partner sofort auch ein anderer Falktor, nemlich die römische Kirche sich einstellte. Erneuerte doch diese seit dem Tode Kaiser Heinrichs VI. alle Ansprüche, die ihr jemals verbrieft worden waren ${ }^{6}$ ).

1) Vgl. Desimoni p. 255 f,

2) Ptolem. Lucens. bei Muratori Script. XI, 1278: Factum fuit iuramentum Lucensi comuni ab Andrea marchioni Massae Lunensis. Vgl. Bonaini, Statuti inediti della città di Pisa I p. 64 n. 1, Desimoni p. 256. Aehnliche Eide leisteten sich gegenseitig auch die Malaspina und die Lucenser, So 1205 Wilhelm Malaspina, in toto suo marchionatu et dominio : Zum J. 1213 berichtet Ptolem. Lurens. ferner: facta fuit promissio per Lucenses consules d. Guilelmo et Opezino Malaspinae de salvandis corum territoriis. - Derselbe ad a. 1218: facta obligatio Lucensi comuni per castellanum Arcis Massae marchionis et castaldionem, Domicellae filiae quondam Guillielmi marchionis Massae etc.

$\left.{ }^{3}\right)$ Statuten von Pisa 1, VI; 3, IX (p. 64, 371). Im J. 1244 heisst es in einer Urkunde: Guillielmus marchio Massae Lunensis, quondam Andreae marchionis Massae Lunensis, pro se et Alberto eius germano quondam suprascripti Andree marchionis, et Conrado marchione eius consorte, et aliis omnibus eius consortibus marchionibus et etiam pro iuribus que ipse Guilelmis marchio habet contra Conradum marchionem etc. locavit etc. Man sieht wie zahlreich die Vettern und wie zersplittert der Besitz war.

4) Im J. 1196 verkauft Markgraf Andreas von Massa den Sarzanesen seinen Antheil an Monte Caprione. Muratori, Ant. Est. p. 260. Desimoni p. 237, $246,256$.

c) S. oben S. 234 Anm. 3.

f) Vgl. Fisker, Forschungen II S. 384 f. 
Aus der Correspondenz Innocenz III. mit den Machthabern in Pisa geht hervor, dass der Papst auf Sardinien selbst als oberster Lehensherr angesehen sein will; er protestirt dagegen, dass der Erzbischof von Pisa sich vom iudex von Cagliari, eben dem Markgrafen Wilhelm von Massa, schwören lässt'1).

Am 13. Dezember 1217 belehnt Papst Honorius III. den Markgrafen Andreas von Massa mit der "rocea Massa" und anderem, was seine Vorfahren von der römischen Kirche zu Lehen gehabt haben ${ }^{2}$ ).

Am 7. April 1227 schreibt Papst Gregor IX. der „domicella Benedicta", er habe dem Bürger Ubald von Pisa befohlen, sie in Freiheit zu setzen und nach der Burg Massa, Bisthums Luna, ziehen zu lassen, die sie als Lehen von der römischen Kirche habe - auch ihre Versorgung aus dem Königreich Cagliari nicht zu hindern'3). Diese Dame war die Tochter des erstgenannten Wilhelm Markgrafen ron Massa ${ }^{4}$ ).

In den Beschwerdebriefen aber, die Gregor IX. am 7. April und am 1. Juli 1239 gegen Kaiser. Friedrich II. richtet, nennt er als. strittige Punkte: terram quidem Sardinie et massam Lunensem; beziehungsweise terram Sardinie et massam Lunensis diocesis ${ }^{5}$ ). Später

1) Vgl. Winkelmann, Regesten Innocenz III., n. 5925. Ebenda n. 5957: W. Markgraf von Massa, iudex von Cagliari.

2) Winkelmann, Regesten Honorius III, n. 62๖4 = Theiner, Cod. dom. 1, 48: Andree marchioni Massanensi - roccam Masse ac aliam terram, quam praedecessores tui habuerunt a Romana ecclesia iure feudi - in feudum concessimus.

3) Winkelmann Reg. n. $6681=$ Auvray I p. 10 n. 16. Die Acten über diesen durch Heiratsgeschichten sehr verwickelten Handel bei L. Auvray, Les registres de Grégoire IX. (tom. I 1896) n. 13-17. Der Papst will, ut per . . abbatem Montis Christi et . . plebanum de Massa, Lunensis diocesis, libere perdncatur ad castrum Massa, quod a Romana ecclesia tenet in feudum (n. 13, cf. 15 und 17). Ubald von Pisa soll sie freigeben, faciens ipsan ad castrum de Massa, Lunensis diocesis, - perduci. Der Papst dringt darauf, ne (Ubaldus) impediat quominus dictae Benedictae de regno Calaritano in expensis debeat provideri (n. 16). Der Sohn der Benedicta ist Schwiegersohn des Ubald, Benedicta selbst wieder verheiratet. Dieser Handel geht n. 36 und n. 37 fort.

4) Muratori Antich. Estens. p. 256 f. Im J. 1218 tritt die ,Domicella c mit Luca in Verbindung. S. oben. Ueber die weiteren Schicksale der Domicella Benedicta, namentlich ihre Heiraten vgl. Desimoni p. 261.

5) Mon. Germ. hist. Epistolae s. XIII, tom. II p. 637 f. $6 \tilde{2} 2$. -- Ficker II S. 446: „Sardinien und Massa*; welches? Im Index, Bd. 3 S. 500, wird die Stelle unter Massa maritima angeführt, während von Massa Lunensis überhaupt nicht die Rede ist. - Ueber die päpstlichen Ansprüche auf Sardinien in der damaligen Zeit, vgl. auch Winkelmann, Reg. n. 6013, 6217, 7201; auf Sardinien und Corsica n. 8187 (im J. 1249). 
ist von der massa Lunensis, so viel ich sehe, nicht mehr die Rede ${ }^{1}$ ), wohl aber von Sardinien und in Verbindung damit von den Markgrafen Malaspina. Im J. 1268 antwortet Papst Clenens IV. den Markgrafen Manfred und Monellus von Malaspina auf ihre ihm vorgelegten Bitten; die eine um Verleihung der Vicarie auf Sardinien lehnt er $a b$, da er hier nicht im friedlichen Besitz sei, auch nicht die zu Vicaren anstellen könne, die selbst Ansprüche auf einen grossen Theil erheben ${ }^{2}$ ).

Es war nur ein kurzer Moment, dass die alten "Verheissungen" auch in Bezug auf Luna wieder auflebten ${ }^{3}$ ). Das Ende der Entwicklung war, dass die Markgrafen in Massa und Carrara sich behaupteten. Im 16. Jahrhundert (1568) wurảe der Markgraf für Massa zum Fürsten erhoben; seit dem 17. Jahrhundert (1664) lautete der Titel: "Herzog von Massa, Fürst von Carrara"4). Unter wechselnden Formen hat diese territoriale Sondergestaltung ihr Dasein bis ins 19. Jahrhundert gefristet; die Benennung der Provinz ist officiell noch in Gebrauch ${ }^{5}$ ). Daneben hat sich im Volkstnunde die Bezeichnung der ganzen Landschaft als "Lunigiana" erhalten ${ }^{6}$ ). Der Bischof führt ietzt den Titel von Sarzana-Brugnato, da seit dem J. 1820 die beiden Diöcesen vereinigt sind ${ }^{7}$ ). Der Golf des alten Luna umfasst den Haupthafen der italienischen Marine im westlichen Theile des Mittelmeeres, Spezia ${ }^{8}$ ). Der Apenninenpass von Pontremoli, in den Zeiten der territorialen Zersplitterung sehr heruntergekommen, beginnt seine alte Bedeutung wieder zu gewinnen; er ist durch die Eisenbahn

1) Ein Archidiacon von Luna erscheint als Rektor der Mark unter Papst Innocenz IV. Vgl. Winkelmann Reg. 8188, 8523, 8543. - Mon. Germ. epistolae saec. XIII, tom. II p. 483. Innocenz IV. im J. 1249 März 29: plebano et capitulo plebis Sancti Stephani Lunensis diocesis ad preces eorum et Barnabei marchionis Malaspinae indulget, ut ad provisionem alicuius per litteras sedis apostolicae vel legatorum eius non teneantur.

2) Winkelmann, Reg. n. 9873.

$\left.{ }^{3}\right)$ Warum Tuscien schliesslich nicht zum Kirchenstaat kam, erörtert Ficker, Forschungen II S. 462 ff.

4) Vgl. Lünig, Cod. Ital. dipl. II, 395. 402. Fỉcker, Vom Reichsfürstenstand § 8亏்.

5) Die Provinz heisst gegenwärtig ,Massa e Carrara ‘. Dazu gehört auch Pontremoli.

6) Wie für ,Friaul der von Forum Julii stammende Name.

7) Die Bischöfe residiren abwechselnd in beiden Orten (Ottenthal).

8) Zwischen Portovenere und Lerici. Von Spezia und Maddalena (an der Nordostseite Sardiniens) aus vertheidigt die italienische Flotte den nördlichen Theil des tymhenischen Meeres. 
Spezia-Parma mittelst Tunnels durchbohrt und unterfahren ${ }^{1}$ ). Auch der Marmor von Carrara hat sich behauptet. Er wird vom kleinen Hafenplatz Lavenza aus versohifft ${ }^{2}$ ). Indem die politischen Sondergestaltungen verflogen, bilden die natürlichen Verhältnisse, von mancherlei Hemmungen befreit, den Ausgangspunkt der modernen Entwicklung ${ }^{3}$ ).

1) Mit Anschluss über Viareggio von Pisa und von Luca her. Bei Aulla zweigt eine Seitenlinie ab, die durch das Serchiothal nach Luca führt. - Ueber die Vernachlässigung dieses wichtigen Verbindungsweges zu seiner Zeit durch díe Sorglosigkeit der Regierungen Parma's u. s. w. findet man eine Bemerkung Böhmers in den Regesten Kaiser Friedrich's II. Vgl. Böhmer-Fícker 2609 a. Ueber den Lauf des Weges im 13. Jahrhundert Ficker ebenda 1665 a, 3672 a. Vgl. auch die Regesten Otto IV., 427 a über den , damals nach Bardone südlich von Fornovo im Quellgebiete des Baches Sporzana, jetzt nach La Cisa an der Wasserscheide benannten Pass". Carrara.

2) Vgl. W. Deecke, Italien, 277 und 386 über Spezia, 190 f. und 387 über

3) Ich bemerke nachträglich, dass das zuerst in Luca 1884 (bei Giusti) erschieriene Werk von Giovan. Sforza über Papst Nicolaus V. (dessen deutsche Ausgabe von $H$. Th. Horak durch den Verf. mit Nachträgen bereichert wurde) für das 14. und 15. Jahrhundert viel ungedrucktes Material verwerthet, namentlich für die Familiengeschichte dieses Papstes sowohl nach der väterlichen wie nach der mütterlichen Seite hin das reichhaltige Notariatsarchiv von Sarzana. Dadurch ist auch clie von der Familie Bonaparte stets behauptete Verwandtschaft mit Papst Nicolaus V. in das richtige Licht gestellt; ein Giovanni Bonaparte war der Neffe der Mutter dieses Papstes (S. 42, vgl. S. 192, 209). Sforza benützte für seine Arbeiten auch mehrere handschriftlich erhaltene Werke; so Landinelli, Origine dell' antichissima città di Luni e sua distruzione, della città di Sarzana e di tutte le cose più notabili appartinenti alla detta città, a tutta la provincia di Luni, alla chiesa lunese ed a'suoi vescovi (a. 1610. Ein Manusc. in Sforza's Besitz). Ferner: E. Gerini, Codex documentorum illustrium ad historicam veritatem Lunexanae provinciae elaboratum. (Msc. in der Bibliothek des königl. Staatșarchirs in Florenz). B. de Rossi, Collettanea copiosissima di memorie e notizie istoriche appartenenti alla città e provincia di Luni (a. 1706). Die von uns in Betracht gezogenen Momente werden darin kaum zur Geltung gelangt sein, da die Uebersicht über das weiter reichende Quellenmaterial mangelte. Dies gilt auch von 'Iargioni Tozzetti, Viaggi fatti in diverse parti della Toscana, und anderen Schriften, die Bormann in Corp. inscript. Latinar. Bd. XI p. 258 f. anführt. - Ueber das Capitelarchiv in Sarzana genügt es auf v. Ottenthals Mittheilungen a. a. $O$. zu verweisen. Im Uebrigen sind die Anmerkungen. zu den Urkundenpublicationen von Ficker und Winkelmann zu vergleichen. 